NASA Technical Memorandum 84592

MIXED-MODE STRAIN-ENERGY-RELEASE RATE

EFFECTS ON EDGE DELAMINATION OF COMPOSITES

T. Kevin 0'Brien

January 1983

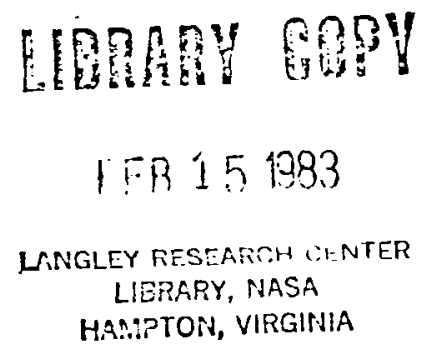





\title{
MIXED-MODE STRAIN-ENERGY-RELEASE RATE EFFECTS \\ ON EDGE DELAMINATION OF COMPOSITES
}

\author{
T. Kevin O'Brien \\ Structures Laboratory \\ U.S. Army Research and Technology Laboratories (AVRADCOM) \\ NASA Langley Research Center \\ Hampton, Virginia 23665
}

\section{SUMMARY}

Unnotched $[ \pm \theta / 0 / 90]_{\mathrm{s}}$ graphite/epoxy laminates, designed to delaminate at the edges under static and cyclic tensile loads, were tested and analyzed. The specimen stacking sequences were chosen so that the total strain-energy-release rate, G, for edge delamination was identical for all three layups. However, each layup had different percentages of crack-opening and shear-mode strainenergy-release rates, $G_{I}$ and $G_{I I}$, respectively. Results with composites made from T300 graphite fibers and 5208 epoxy, a brittle resin, indicated that only $G_{I}$ contributed to delamination onset under static loading. However, results with composites made from $\mathrm{C} 6000$ fibers and H205 epoxy, a tougher resin, indicated that the total $G$ governed the onset of edge delaminations under cyclic loads. In addition, for both materials, the threshold level of $G$ for delamination onset in fatigue was significantly less than the critical $G_{c}$ measured in static tests. Furthermore, although the $66000 / \mathrm{H} 205$ material had a much higher static $G_{c}$ than $T 300 / 5208$, its fatigue resistance was only slightly better. A series of mixed-mode tests, like the ones in this study, may be needed to evaluate toughened-resin composites developed for highly strained composite structures subjected to cyclic loads. 
NOMENCLATURE

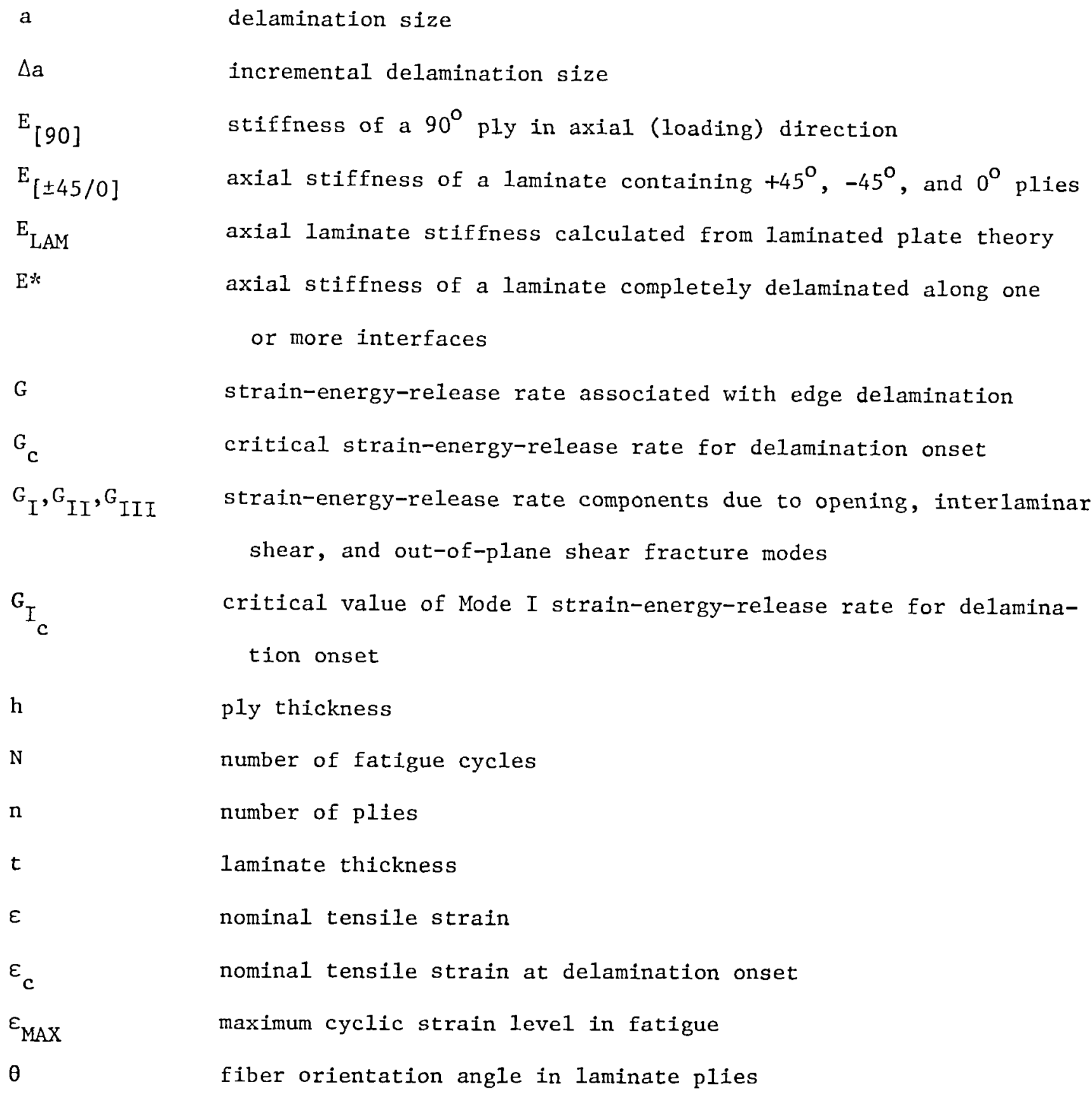


INTRODUCTION

One major obstacle to the application of advanced composite materials in primary aircraft structure is the tendency for these materials to delaminate. Delamination often results in loss of stiffness, strength, and fatigue life [1-4]. Delamination failure criteria are needed to predict the onset and growth of delaminations. One measure of delamination resistance under static loading is interlaminar fracture toughness. The interlaminar fracture toughness, $G_{c}$, of a composite laminate is the critical value of the strain-energy-release rate, $G$, required to cause a delamination to grow. Previously [1], the critical strainenergy-release rate measured at delamination onset in eleven-ply $[ \pm 30 / \pm 30 / 90 / \overline{90}]_{s}$, NARMCO T300/5208 ${ }^{\dagger \dagger}$ graphite/epoxy laminates was used to predict delamination onset in layups with other thicknesses and stacking sequences. Good agreement was found between measured and predicted delamination onset strains. However, before delamination criteria can be generated with confidence, the relative contributions of interlaminar tension and shear to the formation and growth of delaminations must be identified.

The primary goal of this investigation was to determine the effect of different mixed-mode (interlaminar tension and shear) strain-energy-release rate percentages on the formation of edge delaminations in unnotched laminates subjected to static and cyclic tensile loads. Unnotched graphite/epoxy laminates, designed to delaminate at specific interfaces, were analyzed and tested. A parametric study was performed to optimize laminate layups for $\mathrm{G}_{\mathrm{c}}$ measurement (Appendix). A combination of stacking sequences was chosen so that the total

\footnotetext{
The bar over the center $90^{\circ}$ ply denotes one half of a ply thickness. $\dagger^{+}$Use of trade names or manufacturers does not constitute an official endorsement, either expressed or implied, by the National Aeronautics and Space Administration or AVRADCOM.
} 
strain-energy-release rates were the same, but the percentages of interlaminar tension, $G_{I}$, and interlaminar shear, $G_{I I}$, were very different. A closed-form equation [1] was used to calculate total strain-energy-release rates. A quasithree-dimensional finite-element analysis [5] was used to determine $G_{I}$ and $G_{I I}$ percentages using the technique outlined previously [1].

Static tests were performed on T300/5208 laminates. Measured delamination onset strains and corresponding strain-energy-release rates were compared for the layups with the same total $G$ but with different $G_{I}$ and $G_{I I}$ percentages. Results were also compared to $\mathrm{G}_{\mathrm{I}_{\mathrm{c}}}$ measurements from double cantilever beam tests. Static and fatigue tests were performed on Hexcel $\mathrm{C} 6000 / \mathrm{H} 205^{\dagger+}$ graphite/ epoxy laminates. The number of cycles to delamination onset at prescribed maximum cyclic strains (and corresponding strain-energy-release rates) were compared for two layups with the same total $G$ but again with different $G_{I}$ and $G_{I I}$ percentages.

The secondary goal of this investigation was to determine if these static and fatigue tests could be used to establish the relative delamination resistance of different composite materials. Therefore, static and fatigue results for T300/5208 and C6000/H205 were compared. 


\section{STATIC BEHAVIOR}

Delamination Onset Prediction

Previously, the onset of $0 / 90$ interface edge delaminations in $\left[+45_{n} /-45_{n} / 0_{n} /\right.$ $90_{n_{S}}(n=1,2,3)$ T300/5208 graphite/epoxy laminates were predicted from a closedform equation for the total strain-energy-release rate, $G$, for edge delamination [1]. This equation

$$
G=\frac{\varepsilon^{2} t}{2}\left(E_{L A M}-E^{*}\right)
$$

is independent of delamination size. The stiffness quantities, $\mathrm{E}_{\mathrm{LAM}}$ and $\mathrm{E}^{*}$, were calculated from laminated plate theory and the rule of mixtures $[1,2]$. To predict delamination onset, the critical value, $G_{c}$, was calculated from equation (1) using the critical strain, $\varepsilon_{c}$, measured at the onset of $-30 / 90$ interface edge delamination in tension tests on $[ \pm 30 / \pm 30 / 90 / \overline{90}]$ s laminates. Then, equation (1) was rearranged, and this $G_{c}$ was used to predict $\varepsilon_{c}$ in the $\left[+45_{n} /-45_{n} / 0_{n} / 90_{n}\right]_{s}$ laminates. The predictions [1] agreed closely with the data reported [6]. In this study, additional 8-ply and 16-ply specimens were tested to verify these results. Figure 1 shows that the predicted and newly measured values of $\varepsilon_{c}$ also agreed well. The arrow in the stacking sequence shown in figure 1 indicates that delaminations were modeled in the 0/90 interfaces. Figure 2 shows a micrograph of the specimen edge showing the delamination location through the thickness for the 8-ply laminates. Delaminations formed at, and wandered between, the $0 / 90$ interfaces where they were assumed to occur. This same detail was observed for the 16-ply laminates.

Because these results verify the thickness dependence of delamination onset observed in the data and show good quantitative agreement with predicted delamination onset strains, the strain-energy-release rate appears to be a viable 
parameter for predicting delamination behavior. However, G, as calculated using equation (1), is a total strain-energy-release rate consisting of both $G_{I}$ and $\mathrm{G}_{\mathrm{II}}$. As previously mentioned, to evaluate the relative contributions of the two fracture modes to edge delamination, three different quasi-isotropic layups, each with the same total $G$ but different percentages of $G_{I}$ and $G_{I I}$, were analyzed and tested. The total $G$ was calculated from equation (1), and the relative percentages of $G_{I}$ and $G_{I I}$ were calculated by a finite-element analysis [5] using the technique outlined previously [1].

Analysis

Three different quasi-isotropic layups were analyzed. Laminate A was $[ \pm 45 / 0 / 90]_{S}$, laminate $B$ was $[0 / \pm 45 / 90]_{S}$, and laminate $C$ was $[45 / 0 /-45 / 90]_{S}$ All three have $90^{\circ}$ plies in the center to create high interlaminar tensile stresses at the $\theta / 90$ interfaces, where $\theta$ is either $0^{\circ}$ or $-45^{\circ}$. Delaminations were modeled at the $0 / 90$ interfaces for laminate $A$, and at the $-45 / 90$ interfaces for laminates $B$ and $C$.

Because these layups are all quasi-isotropic, their initial laminate stiffnesses, $E_{L A M}$, are identical. The rule of mixtures equation for stiffness after the $\theta / 90$ interfaces are completely delaminated is

$$
E^{*}=\frac{6 E_{[ \pm 45 / 0]}+2 E_{[90]}}{8}
$$

The stiffness of a $[ \pm 45 / 0]_{s}$ laminate, calculated from laminated plate theory, is identical for all three permutations of $+45^{\circ},-45^{\circ}$, and $0^{\circ}$ plies in layups $A, B$, and C. Hence, $E^{*}$ is also identical for the three layups. Therefore, the total strain-energy-release rate calculated from equation (1), for a given nominal strain, $\varepsilon$, and laminate thickness, $t$, will be identical for laminates $A, B$, and $C$. 
Figure 3 shows the finite element meshes used to calculate strain energy release rates. Delaminations were modeled in the $\theta / 90$ interfaces previously specified. The virtual crack extension technique outlined in reference 1 was used to compute strain-energy-release rates from nodal forces and displacements calculated before and after an incremental delamination extension, respectively. Figure 4 shows $G$ calculated with the coarse finite element mesh and a remote strain of 0.004 , plotted as a function of delamination size normalized by ply thickness. As was previously observed for other layups [7-10], G , and total G are independent of delamination size, once the delamination has grown one to two ply thicknesses in from the specimen edge. As indicated in figure 4, the total $G$ calculated from finite element analysis by suming $G_{I}$ and $G_{I I}$ agrees closely with the total $\mathrm{G}$ calculated independently from equation (1). Figure 4 also shows the percentage of the total $G$ attributed to the opening mode, $G_{I}$. The opening mode, $\mathrm{G}_{\mathrm{I}}$, was 85 percent, 57 percent, and 28 percent of the total G for laminates A, C, and B respectively. The interlaminar shear mode, $G_{I I}$, constituted the remainder. The out-of-plane shear mode, G $G_{I I}$, was negligible for all three layups.

Refinement of the coarse finite element mesh from one to three elements through a ply thickness had a negligibly small effect on the $G_{I}$ percentages, as shown in figure 4 for $a / h=3.7$. The $G$ curves in figure 4 were generated assuming material properties in table 1 [6]. In addition, a three-dimensional set of material properties were used, based on the work of $\mathrm{Kriz}$ [11], to account for the different in-plane and through thickness moduli and Poisson's ratios. These modified properties had only a small influence on the $G_{I}$ percentages, as shown in figure 4 for $a / h=9.3$. 


\section{Experiments}

Two $305 \mathrm{~mm}$ by $305 \mathrm{~mm}$ panels were made for each of the three layups using the same roll of T300/5208 graphite/epoxy prepreg. Each panel was cured in an autoclave using the manufacturer's prescribed curing cycle. Five $254 \mathrm{~mm}$ by $38 \mathrm{~mm}$ (10-by-1.5 inch) coupons were then cut from each panel and tested in tension using apparatus and procedures described in references 1 and 2. A pair of LVDT's were mounted on either side of the specimens to measure nominal strain over a $102 \mathrm{~mm}$ ( 4 in.) gage length. Dye-penetrant-enhanced radiographs were taken to confirm the onset of edge delamination, which was indicated by a deviation from a linear stress-strain curve. Photomicrographs of specimen edges shown in figures 2 and 5 indicated that delaminations formed only in the interfaces that were assumed to delaminate in the analysis.

\section{Results and Discussion}

Laminates $A, B$, and $C$ all have the same total $G$. Therefore, if total $G_{C}$ governs the onset of edge delamination, $\varepsilon_{c}$ would be identical for all three layups. However, if only $G_{I}$ governs delamination onset, then $\varepsilon_{c}$ would be lowest for the layup with the highest $G_{I}$ percentage. Hence, $\varepsilon_{c}$ would be lowest for $A$, highest for $B$, with $C$ somewhere in between. Figure 6 shows the measured $\varepsilon_{c}$ values. The symbols represent the mean of ten tests, and the brackets show the scatter. The mean values of $\varepsilon_{c}$ were lowest for layup $A$ and highest for layup $B$, with $C$ in between. Hence, $G_{I}$, and not the total $G$, appears to control the onset of edge delamination for static loading.

Figure 7 shows the critical values of strain-energy-release rate, $G_{c}$, calculated from equation (1) with the $\varepsilon_{c}$ data for the three layups. The open symbols and brackets represent the mean values and scatter bands, respectively. The solid symbols represent corresponding values of $\mathrm{G}_{\mathrm{I}_{\mathbf{c}}}$ calculated from the percentage of $G_{c}$ that was due to $G_{I}$. For laminates $A$ and $C$, these $G_{I_{C}}$ values 
agree fairly well with $G_{I_{C}}$ data from unidirectional double cantilever beam (DCB) flexure tests [12]. However, for laminate $B$, which had the lowest $G_{I}$ percentage, the estimated $G_{I_{C}}$ was well below $G_{I_{C}}$ measured by the DCB tests.

Both laminates $B$ and $C$ exhibited large scatter in $G_{c}$ data and, hence, in $\mathrm{G}_{\mathrm{I}}$ values. Figure 8 shows that both of these laminates developed many $90^{\circ} \mathrm{p} 1 \mathrm{y}$ cracks before the onset of delamination, as seen in sequential dye-penetrantenhanced radiographs taken at load increments throughout the tests. Previously, Talug and Reifsnider $[13,14]$, and more recently Crossman, Wang, and Law [8,9], showed that interlaminar tensile stresses can develop at ply interfaces at matrix crack tips. Perhaps, the interaction of these stresses with the interlaminar edge stresses due to Poisson's mismatch led to the large $G_{c}$ scatter observed in layups $B$ and $C$ which developed many cracks before delamination onset. Furthermore, in layups like $B$ where the $G_{I}$ percentage is low, these stresses may have a significant effect on the apparent mean values of $\mathrm{G}_{\mathrm{I}_{c}}$. Hence, care should be taken to avoid extensive $90^{\circ}$ ply cracking before delamination onset in layups where the edge delamination test is used to measure interlaminar fracture toughness. Matrix ply cracking can be reduced by optimizing specimen layups to minimize the $\varepsilon_{c}$ required to measure a given $G_{c} \cdot A[ \pm 35 / 0 / 90]_{s}$ family of layups appears to be optimal (see Appendix). Layups from this family were used to study delamination resistance in fatigue in the next section. In addition, concern about $90^{\circ}$ ply cracking influencing $G_{C}$ measurements is diminished for tougher resin composites where $90^{\circ}$ ply cracking is suppressed [7]. For this reason, C6000/H205 graphite/epoxy composites were analyzed and tested to study mixed-mode effects in fatigue. 


\section{FATIGUE BEHAVIOR}

Analysis

Cyclic loading may cause extensive delamination in graphite/epoxy laminates, even for stacking sequences that do not delaminate under static loads. Therefore, it is necessary to characterize delamination resistance in fatigue as well as in static loading. To this end, two layups with the same total strain-energy-release rate, but relatively high and low $G_{I}$ percentages, were analyzed and tested. Specifically, these layups were $[ \pm 35 / 0 / 90]_{S}$ and $[0 / \pm 35 / 90]_{S^{*}}$ The $35^{\circ}$ angle was chosen from a parametric study to optimize the layup for the edge delamination test for measuring interlaminar fracture toughness (see Appendix). Both laminates have $90^{\circ}$ plies in the center to create high interlaminar tensile stresses.

Figure 9 compares $G$ and $G_{I}$, calculated at a remote strain of 0.004 , for two $[ \pm \theta / 0 / 90]_{s}$ families. Results for both $[ \pm \theta / 0 / 90]_{s}$ families were calculated using the T300/5208 material properties in table 1 [6]. The quasiisotropic results were replotted from figure 4. As indicated by the arrows in figure 9, delaminations were modeled in the $0 / 90$ and $-35 / 90$ interfaces for the $[ \pm 35 / 0 / 90]_{s}$ and $[0 / \pm 35 / 90]_{s}$ layups, respectively. The open symbols show the total strain-energy-release rates, calculated by summing $G_{I}$ and $G_{I I}$. The solid symbol shows that these total $G^{\prime} s$ agree well with values calculated independently from equation (1). Also shown in figure 9 are the $G_{I}$ calculations from finite-element analyses.

Figure 9 illustrates that changing $\theta$ from $45^{\circ}$ to $35^{\circ}$ will result in a higher total $G$ at the same remote strain, and a wider range of Mode I 
percentages for the three different stacking sequence permutations. Furthermore, as was previously noted [7], $G_{I}$ percentages are controlled by the stacking sequence and are very insensitive to large changes in the matrixdominated lamina properties, as long as the fiber-dominated moduli are relatively unchanged. Table 2 shows the influence of material properties on $G_{I}$ percentages for the $[ \pm 35 / 0 / 90]_{S}$ family of layups. The range of Mode I percentages was slightly greater for $\mathrm{T} 300 / 5208$ than $\mathrm{C} 6000 / \mathrm{H} 205$, due primarily to the lower $E_{11}$ value for the $\mathrm{C} 6000 / \mathrm{H} 205$ composite (table 1 ).

\section{Experiments}

Static and constant-amplitude, strain-controlled $(R=0.2, f=10 \mathrm{~Hz})$ cyclic tests were performed on $[ \pm 35 / 0 / 90]_{S}$ and $[0 / \pm 35 / 90]_{s}$ layups made of C6000/H205 graphite/epoxy. The H205 epoxy was chosen because, as a composite matrix, it has significantly greater interlaminar fracture toughness than the 5208 epoxy $[7,15]$. Furthermore, $90^{\circ}$ ply cracking was greatly suppressed in $\mathrm{C} 6000 / \mathrm{H} 205[ \pm 30 / \pm 30 / 90 / \overline{90}]_{S}$ laminates used to measure interlaminar fracture toughness [7]. Hence, the tougher $\mathrm{H} 205$ matrix was expected to suppress $90^{\circ}$ ply cracking before delamination in the $[0 / \pm 35 / 90]_{s}$ layup that has a low $G_{I}$ percentage.

Tests were run until the first indication of delamination onset. Indications involved a combination of visual detection, audible detection, and measured stiffness loss indicated by a discontinuous jump in the load deflection plot during static tests or a drop in cyclic load during the straincontrolled fatigue tests. At the first sign of delamination, loading was stopped and a dye-penetrant-enhanced radiograph was taken to verify the presence of delamination. 
Figure 10 shows typical dye-penetrant-enhanced radiographs for the $66000 /$ H205 laminates taken just after delamination onset in fatigue. Figure 11 shows that delaminations formed in the $0 / 90$ interfaces of $[ \pm 35 / 0 / 90]_{s}$ and in the $-35 / 90$ interfaces of the $[0 / \pm 35 / 90]_{s}$ layups as modeled. The delaminations wandered through the $90^{\circ}$ plies to the symmetric $\theta / 90$ interfaces. There was no evidence of significant $90^{\circ}$ ply cracking before delamination during either the static or cyclic loading.

Results and Discussion

Figure 12 shows the delamination onset strains as a function of fatigue cycles for the two C6000/H205 layups chosen from the $[ \pm 35 / 0 / 90]_{s}$ family. Delamination onset strains for static loading are shown at $\mathrm{N}=0$ in this figure. Delaminations formed at the edge of $[ \pm 35 / 0 / 90]_{s}$ layups before failure. However, the $[0 / \pm 35 / 90]_{s}$ layups fractured into two pieces before delaminations formed at the edge. These layups have the same total G, but did not delaminate at the same strain. Hence, total $G_{c}$ does not control delmaination onset for static loading. Because the $[ \pm 35 / 0 / 90]_{s}$ layup that did delaminate has a very high $G_{I}$ percentage, then $G_{I}$ probably plays the dominant role under static loading as was observed earlier for T300/5208. However, quantitative verification would require performing static tests on composites with higher fiber failure strains (see Appendix).

The fatigue data in figure 12 show the number of cycles applied at the onset of edge delamination for a range of maximum cyclic strains. Fatigue cycles are plotted on a linear scale to show the steep reduction in the maximum cyclic strain for delamination onset with increasing fatigue cycles. Eventually, a plateau is reached that is tantamount to an endurance limit for delamination onset. Below this level, no delaminations formed. Data points 
with arrows indicate runouts at $10^{6}$ cycles. Figure 12 demonstrates that delaminations form at different strains in the two layups under static loading. However, delaminations form at nearly identical numbers of fatigue cycles at the same maximum cyclic strains in the two layups.

Static and constant-amplitude fatigue data for $[ \pm 45 / 0 / 90]_{S} \mathrm{~T} 300 / 5208$ laminates are also shown in figure 12. These fatigue data were generated in loadcontrolled tests [3]. However, these data can easily be transferred to maximum cyclic strains since no significant stiffness loss occurs before delamination onset $[1,2]$. The endurance limit for delamination onset, $1 . e .$, the maximum cyclic strain at which no delamination occurs at $10^{6}$ cycles, is higher for C6000/H205 than for T300/5208. However, because strain endurance 1imits will decrease with increasing laminate thickness [3], comparisons of the fatigue delamination resistance of materials should be presented in terms of strain-energyrelease rates.

Figure 13 shows critical $G_{c}$ values for delamination onset, calculated from equation (1), as a function of fatigue cycles. For static tests $(N=0), G_{c}$ values were calculated from the $\varepsilon_{c}$ data shown in figure 12. For fatigue tests $(N>0), G_{c}$ values were calculated from the $\varepsilon_{\text {MAX }}$ data shown in figure 12 . The $G_{c}$ values for the $[ \pm 35 / 0 / 90]_{S}$ and $[0 / \pm 35 / 90]_{S}$ layups under static loading are obviously different; however, the $G_{C}$ values under cyclic loading for the two layups are nearly identical. Hence, although $G_{I}$ may govern delamination onset under static loading for the $\mathrm{C} 6000 / \mathrm{H} 205$ composite, the total $\mathrm{G}$ appears to govern the threshold for delamination onset in fatigue. Obviously, the interlaminar shear that is present may not contribute to delamination under static loading, but contributes fully to delamination under cyclic loading. of course, the difference in static versus fatigue behavior is not simply a matter of 
adding the interlaminar shear contribution, because the threshold value of G for fatigue is much less than the static $G_{c}$. Furthermore, if we were to consider the H205 matrix material as a toughened resin alternative to 5208 , figure 13 shows a significant improvement in the static $G_{c}$, yet the magnitude of this improvement for the $G_{c}$ threshold in fatigue is much less. Hence, a series of mixed-mode static and cyclic tests, like those performed in this study, may be needed to evaluate toughened resin composites developed for highly strained composite structures subjected to cyclic loads. 


\section{CONCLUSIONS}

Unnotched composite laminates, designed to delaminate at the edge under static and cyclic tensile loads, were analyzed and tested. The specimen stacking sequences were chosen so that the total strain-energy-release rate, G, for edge delamination was identical for all three layups. However, each layup had different percentages of crack opening and shear mode strain-energy-release rates, $G_{I}$ and $G_{I I}$, respectively. Static and fatigue tests were conducted on T300/5208 and C6000/H205 graphite/epoxy laminates. Based on the analysis and experiments conducted, the following conclusions have been reached:

(1) The interlaminar crack opening mode strain-energy-release rate, $G_{I}$, controls the onset of edge delamination under static loading.

(2) The total mixed-mode (interlaminar tension and shear) strainenergy-release rate controls the onset of edge delamination under cyclic loads.

(3) The threshold value of strain-energy-release rate for delamination onset in fatigue is significantly less than the corresponding value measured in a static test.

(4) Based on a comparison of T300/5208 and C6000/H205 laminates, the improved delamination resistance provided by the toughened resin (H205) composite was much larger for static loading than fatigue loading.

(5) A series of mixed-mode static and cyclic tests, like those performed In this study, may be needed to evaluate toughened resin composites developed for highly strained composite structures subjected to cyclic loads. 
APPENDIX - Layup Optimization for $G_{c}$ Measurements

Background

Recently, the edge delamination test was used to measure the interlaminar fracture toughness of toughened resin composites in reference 7 . In that study, eleven-ply $[ \pm 30 / \pm 30 / 90 / \overline{90}]$ s laminates, with C6000 graphite fibers reinforcing Hexel 205 and rubber-toughened F185 resins, were tested to determine critical values of mixed-mode interlaminar fracture toughness, $G_{c}$. These edge delamination tests were successful in discriminating the improved toughness of the different matrices. However, in order to achieve a better quantitative comparison of interlaminar fracture toughness, layups with a wide range of mixed-mode percentages are needed. In addition, fiber-dominated layups, containing zero degree plies, may be needed for testing composites with toughened resins (like the rubber-toughened F185 resIn) that exhibit material nonlinearity in the individual plies of the $[ \pm 30 / \pm 30 / 90 / \overline{90}]_{\text {s }}$ layup before delamination onset [7]. Therefore, a parametric study was undertaken to develop optimal layups for the edge delamination test for measuring interlaminar fracture toughness.

The ideal layup for the edge delamination test would be one that requires the fewest number of plies yet delaminates at the lowest possible strain for a given interlaminar fracture toughness. Minimizing the number of plies will help conserve the amount of constituent material needed to make the composite specimen. This is of particular concern when only small quantities of resin are available. Minimizing $\varepsilon_{c}$ for measuring a given $G_{c}$ will help insure that edge delamination precedes extensive $90^{\circ}$ ply cracking and/or fiber and, hence, laminate failure. Some $90^{\circ}$ plies must be kept in the center of the laminate to insure a high Poisson's mismatch [16]. 


\section{$[ \pm \theta / 90]_{s}$ Family Optimization}

Perhaps the simplest layup would be a $[ \pm \theta / \overline{90}]_{s}$ five-ply laminate with delaminations occurring in the $-\theta \overline{90}$ interfaces. As $\theta$ varies, the $\left(E_{L A M}-E^{*}\right)$ term in equation (1) will change. Figure 14 shows the variation in delamination onset strains, $\varepsilon_{c}$, required for various $[ \pm \theta / \overline{90}]_{s}$ laminates to measure an interlaminar fracture toughness of $0.15 \mathrm{~kJ} / \mathrm{m}^{2}$. As shown in figure 14 , the lowest $\varepsilon_{\mathrm{c}}$ occurs in the vicinity of $30^{\circ}$.

Furthermore, by noting that $\varepsilon_{c}$ is proportional to $1 / \sqrt{t}$, increasing the laminate thickness, $t$, will also lower the $\varepsilon_{c}$ required to measure a given $G_{c}$. This may be accomplished in two ways: first, by increasing the number of angle plies, i.e., $\left[( \pm \theta)_{\mathrm{n}} / \overline{90}\right]_{\mathrm{s}}$, or second, by increasing the number of $90^{\circ} \mathrm{p} 1$ ies, i.e., $\left[ \pm \theta / \overline{90}_{n}\right]_{s}$, where $n=1,2,3 \ldots$ Figure 15 shows the effect of both techniques on the $\varepsilon_{c}$ required to measure a given $G_{c}$. For a given number of $90^{\circ} \mathrm{p} 1$ ies, $n$, the $\left[( \pm 30)_{2} / 90_{n}\right]_{s}$ layup requires a lower $\varepsilon_{c}$ than the $\left[ \pm 30 / 90_{n}\right]_{s}$ layup to measure the same $G_{c}$. However, increasing the number of angle plies has the disadvantage of rapidly increasing the laminate thickness and, hence, the amount of material needed to make the specimen. Increasing $\pm \theta$ plies requires adding four new plies each time. As shown in figure 15, increasing the number of $90^{\circ}$ plies will also lower the $\varepsilon_{c}$ required to measure a given $G_{c} \cdot$ However, increasing the number of $90^{\circ}$ plies has the disadvantage, when taken to extremes, of increasing the contribution of the $90^{\circ}$ ply cracks to laminate stiffness loss. Such a significant contribution would have to be included in the $\mathrm{E}^{*}$ calculation [1]. In addition, if the number of $90^{\circ}$ plies grouped in the center is large enough, delaminations can form due to the interlaminar stress fields that develop in the interface at the $90^{\circ}$ ply crack tips and not due to the large Poisson's mismatch $[8,9,17]$. However, both these concerns about increasing $90^{\circ}$ ply thickness are diminished by the tendency for $90^{\circ}$ ply cracking to be suppressed in composites with toughened-resin matrices [7]. 
Based on this parametric study, the eleven-ply $[ \pm 30 / \pm 30 / 90 / \overline{90}]_{\text {s }}$ layup (shown on figure 15 as $\left[( \pm 30)_{2} / 90_{n}\right]_{s}$ where $n=3 / 2$ ) previously used in reference 7 is a good candidate layup to measure interlaminar fracture toughness. However, because material nonlinearity may appear before delamination for composites with toughened matrix resins [7], an alternate layup was sought for the edge delamination test.

\section{$[ \pm \theta / 0 / 90]_{S}$ Family Optimization}

The $[ \pm \theta / 0 / 90]_{S}$ family of layups was considered because including the $0^{\circ} \mathrm{ply}$, i.e., having a fiber-dominated layup, would suppress the material nonlinearity. Figure 14 shows the variation in delamination onset strain, $\varepsilon_{c}$, for various $[ \pm \theta / 0 / \overline{90}]_{S}$ layups required to measure an interlaminar fracture toughness of $0.15 \mathrm{~kJ} / \mathrm{m}^{2}$. The lowest $\varepsilon_{\mathrm{c}}$ occurs in the vicinity of $35^{\circ}$. Figure 15 shows the effect on $\varepsilon_{c}$ of increasing $90^{\circ}$ ply thickness for $\left[ \pm 35 / 0 / 90_{n}\right]_{s}$ laminates. The same concerns mentioned earlier about increasing $90^{\circ}$ ply thickness would also apply to this layup, but would be diminished by the tendency for $90^{\circ} \mathrm{ply}$ cracking to be suppressed in toughened resin matrices [7]. As shown in figure 15, the largest reduction in $\varepsilon_{c}$ results between $n=1 / 2$ and $n=1$. Hence, the $8-p 1 y[ \pm 35 / 0 / 90]_{s}$ laminate is a good candidate for the edge delamination test.

Furthermore, the finite-element analysis performed in this study (table 2) shows that the three permutations of the $+35^{\circ},-35^{\circ}$, and $90^{\circ}$ plies will result in three 8-ply layups with the same total $G$ but a wide range of $G_{I}$ and $G_{I I}$ percentages. Hence, the $[ \pm 35 / 0 / 90]_{s}$ family of layups should be very useful for evaluating mixed-mode effects in toughened resin composites. One potential disadvantage with these layups, however, is that the range of toughness measurements that can be made is limited by the ultimate tensile strain of the 
fiber, which controls the nominal failure strain of a fiber-dominated laminate [2]. However, the new high failure strain (> 1.4 percent) graphite fibers currently on the market will increase the range of $G_{c}$ measurements possible beyond the 1 percent limitation illustrated in figures 14 and 15 .

\section{Summary}

As a result of this parametric study, the eleven-p1y $[ \pm 30 / \pm 30 / 90 / \overline{90}] \mathrm{s}$ and the $8-p l y[ \pm 35 / 0 / 90]_{S}$ layups appear to be good candidates for the edge delamination test for measuring interlaminar fracture toughness. Furthermore, the three permutations of the 8-p1y layup, i.e., $[ \pm 35 / 0 / 90]_{s},[+35 / 0 /-35 / 90]_{s}$, and $[0 / \pm 35 / 90]_{S}$, all have the same total $G$ but a wide range of $G_{I}$ and $G_{I I}$ percentages. Hence, these three layups are good candidates for studying mixedmode effects in toughened resin composites. 


\section{REFERENCES}

[1] O'Brien, T. K.: Characterization of Delamination Onset and Growth in a Composite Laminate. Damage in Composites, ASTM STP 775, American Society for Testing and Materials, June 1982, pp. 140-167. Also NASA TM-81940, 1981.

[2] O'Brien, T. K.: The Effect of Delamination on the Tensile Strength of Unnotched, Quasi-Isotropic, Graphite/Epoxy Laminates. Proceedings of the SESA/JSME Joint Conference on Experimental Mechanics, Part I, Hawaii, May 1982, pp. 236-243.

[3] O'Brien, T. K.: Tension Fatigue Behavior of Quasi-Isotropic Graphite/ Epoxy Laminates. Proceedings of the Third Ris $\phi$ International Symposium on Metallurgy and Materials Science: Fatigue and Creep of Composite Materials, Roskilde, Denmark, Sept. 6-10, 1982, pp. 259-264.

[4] Byers, B. A.: Behavior of Damaged Graphite/Epoxy Laminates Under Compression Loading. NASA CR-159293, August 1980, p. 63.

[5] Raju, I. S.; and Crews, J. H., Jr.: Interlaminar Stress Singularities at a Straight Free Edge in Composite Laminates. Computers and Structures, vol. 14, no. 1-2, 1981, pp. 21-28.

[6] Rodini, B. T., Jr.; and Eisenmann, J. R.: An Analytical and Experimental Investigation of Edge Delamination in Composite Laminates. Fibrous Composites in Structural Design, Plenum, New York, 1980, pp. 441-457.

[7] O'Brien, T. K.; Johnston, N. J.; Morris, D. H.; and Simonds, R. A.: A Simple Test for the Interlaminar Fracture Toughness of Composites. SAMPE Journal, vol. 18, no. 4, July/August 1982, pp. 8-15.

[8] Law, G. E.: Fracture Analysis of $\left( \pm 25 / 90_{n}\right)$ Graphite Epoxy Composite Laminates. Ph.D. dissertation, Drexel University, Philadelphia, PA, June 1981.

[9] Crossman, F. W.; Warren, W. T.; Wang, A. S. D.; and Law, G. E.: Initiation and Growth of Transverse Cracks and Edge Delamination in Composite Laminates. J. of Composite Materials, Supplemental Volume (1980), pp. 88-106.

[10] Wang, S. S.: Edge Delamination in Ang1e P1y Composite Laminates. Proceedings of the 22nd AIAA, ASME, ASCE, AHS Structures, Structura1 Dynamics, and Materials Conference, Part I, Atlanta, GA, April 1981, pp. 473-484.

[11] Kriz, R. D.; and Stinchcomb, W. W.: Elastic Moduli of Traversely Isotropic Graphite Fibers and Their Composites. Experimental Mechanics, vol. 19, no. 2, February 1979, pp. 41-49.

[12] Wilkins, D. J.; Eisenmann, J. R.; Camin, R. A.; Margolis, W. S.; and Benson, R. A.: Characterizing Delamination Growth in Graphite Epoxy. Damage in Composites, ASTM STP 775, American Society for Testing and Materials, June 1982, pp. 168-183. 
[13] Talug, A.; and Reifsnider, K. L.: Analysis of Stress Fields in Composite Laminates With Interior Cracks. Fibre Science and Technology, vol. 12, 1979, pp. 201-215.

[14] Reifsnider, K. L.; and Talug, A.: Analysis of Fatigue Damage in Composite Laminates. International Journal of Fatigue, vo1. 3, no. 1, January 1980, pp. 3-11.

[15] Bascom, W. D.; Bitner, J. L.; Moulton, R. J.; and Siebert, A. R.: The Interlaminar Fracture of Organic-Matrix, Woven Reinforcement Composites. Composites, vo1. II, 1980, pp. 9-18.

[16] Pagano, N. J.; and Pipes, R. B.: Some Observations on The Interlaminar Strength of Composite Laminates. International Journal of Mechanical Sciences, vol. 15, 1973, pp. 679-688.

[17] Crossman, F.W.; and Wang, A. S. D.: The Dependence of Transverse Cracking and Delamination on Ply Thickness in Graphite/Epoxy Laminates. Damage in Composite Materials, ASTM STP 775, American Society for Testing and Materials, 1982, pp. 118-139. 
TABLE 1--Lamina properties.

\begin{tabular}{|c|c|c|c|c|}
\cline { 2 - 4 } & $\mathrm{E}_{11}, \mathrm{GPa}$ & $\mathrm{E}_{22}, \mathrm{GPa}$ & $\mathrm{G}_{12}, \mathrm{GPa}$ & $\nu_{12}$ \\
\hline $\mathrm{T} 300 / 5208$ & 134 & 10.2 & 5.5 & 0.30 \\
$\mathrm{C} 6000 / \mathrm{H} 205$ & 125 & 8.4 & 5.3 & 0.33 \\
\hline
\end{tabular}

TABLE 2--Influence of material properties on $G_{I}$ percentage.

\begin{tabular}{|c|c|c|c|}
\cline { 2 - 4 } & {$[ \pm 35 / 0 / 90]_{s}$} & {$[+35 / 0 /-35 / 90]_{s}$} & {$[0 / \pm 35 / 90]_{s}$} \\
\hline $\mathrm{T} 300 / 5208$ & $90 \%$ & $58 \%$ & $22 \%$ \\
$\mathrm{C} 6000 / \mathrm{H} 205$ & $88 \%$ & $59 \%$ & $25 \%$ \\
\hline
\end{tabular}




$$
\left[+{ }^{4} 5^{-45}{ }^{-10}{ }_{n} / 90_{n}\right]_{S} \text { GRAPHITE EPOXY }
$$

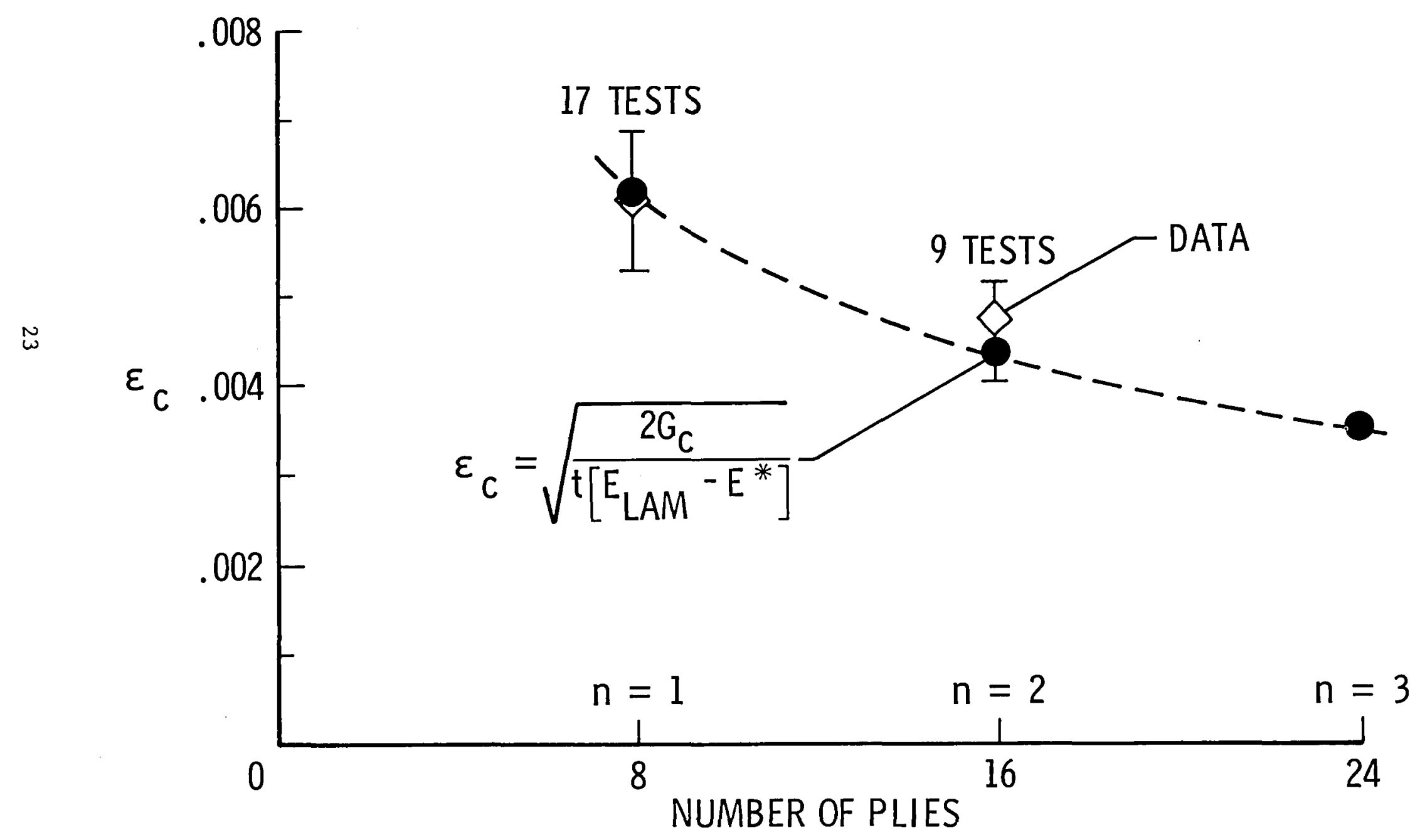

Fig. 1--Delamination onset prediction. 


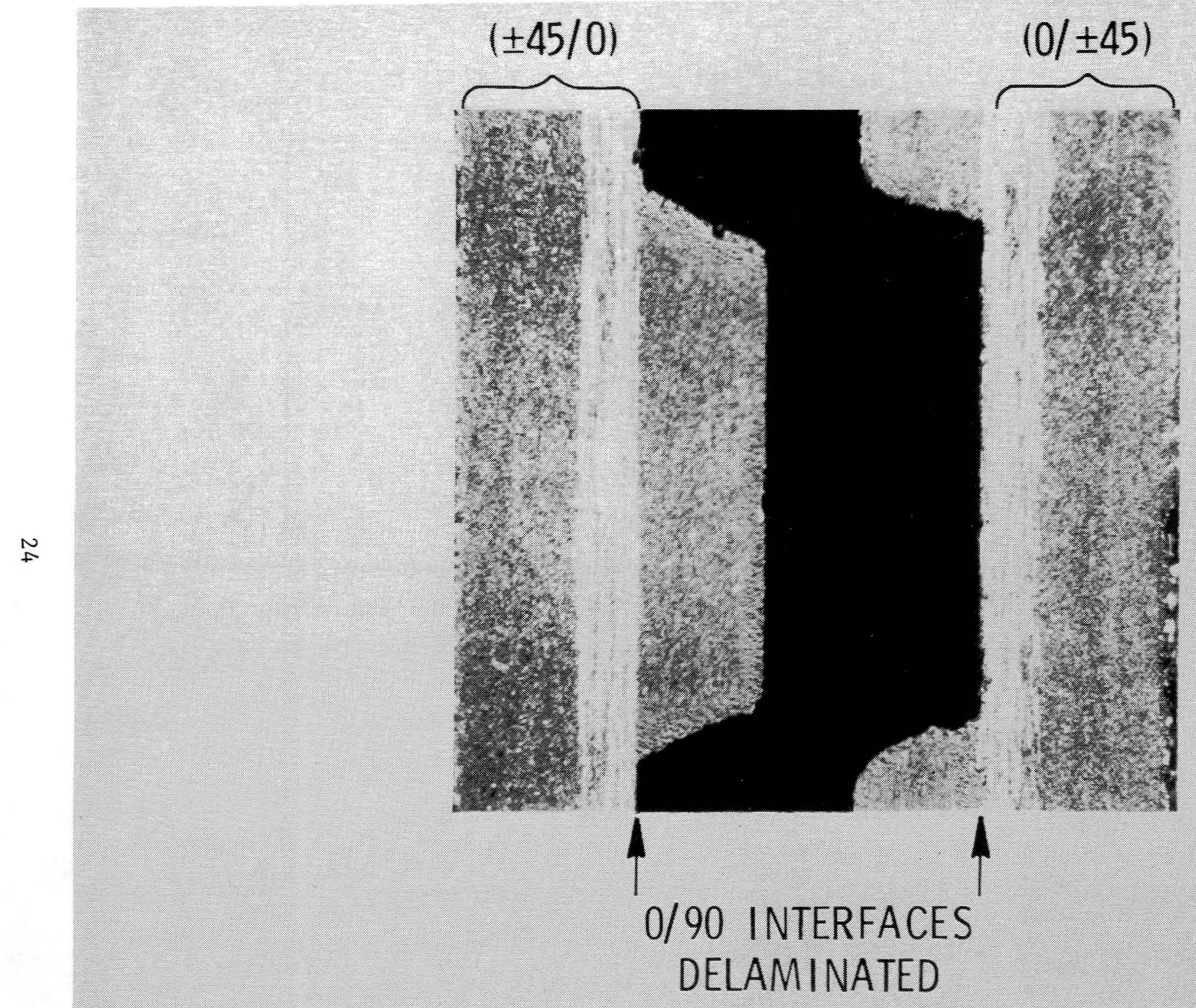

Fig. 2--Delaminated straight edge, $[ \pm 45 / 0 / 90]_{S}$ T300/5208 laminate. 


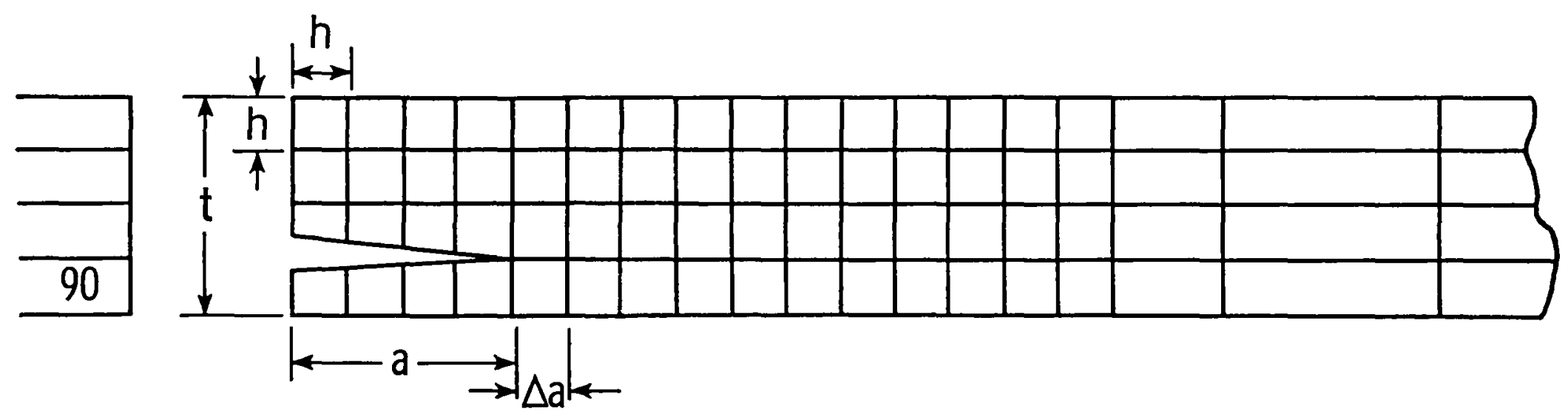

䜣

(a) COARSE MESH

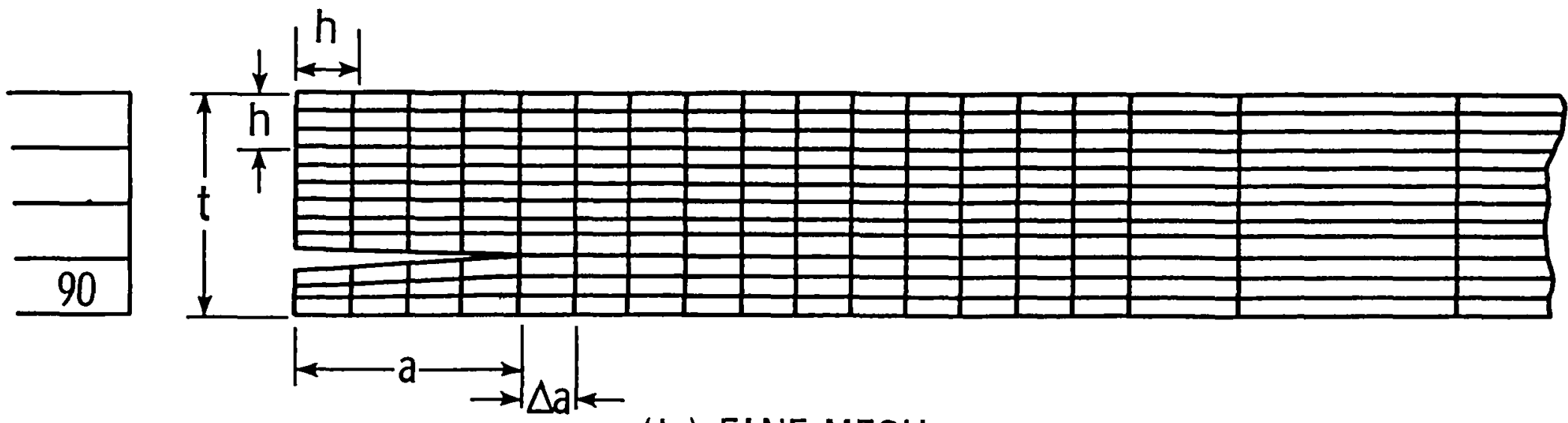

(b) FINE MESH

Fig. 3--Finite-element grids for calculating strain-energy-release rates. 


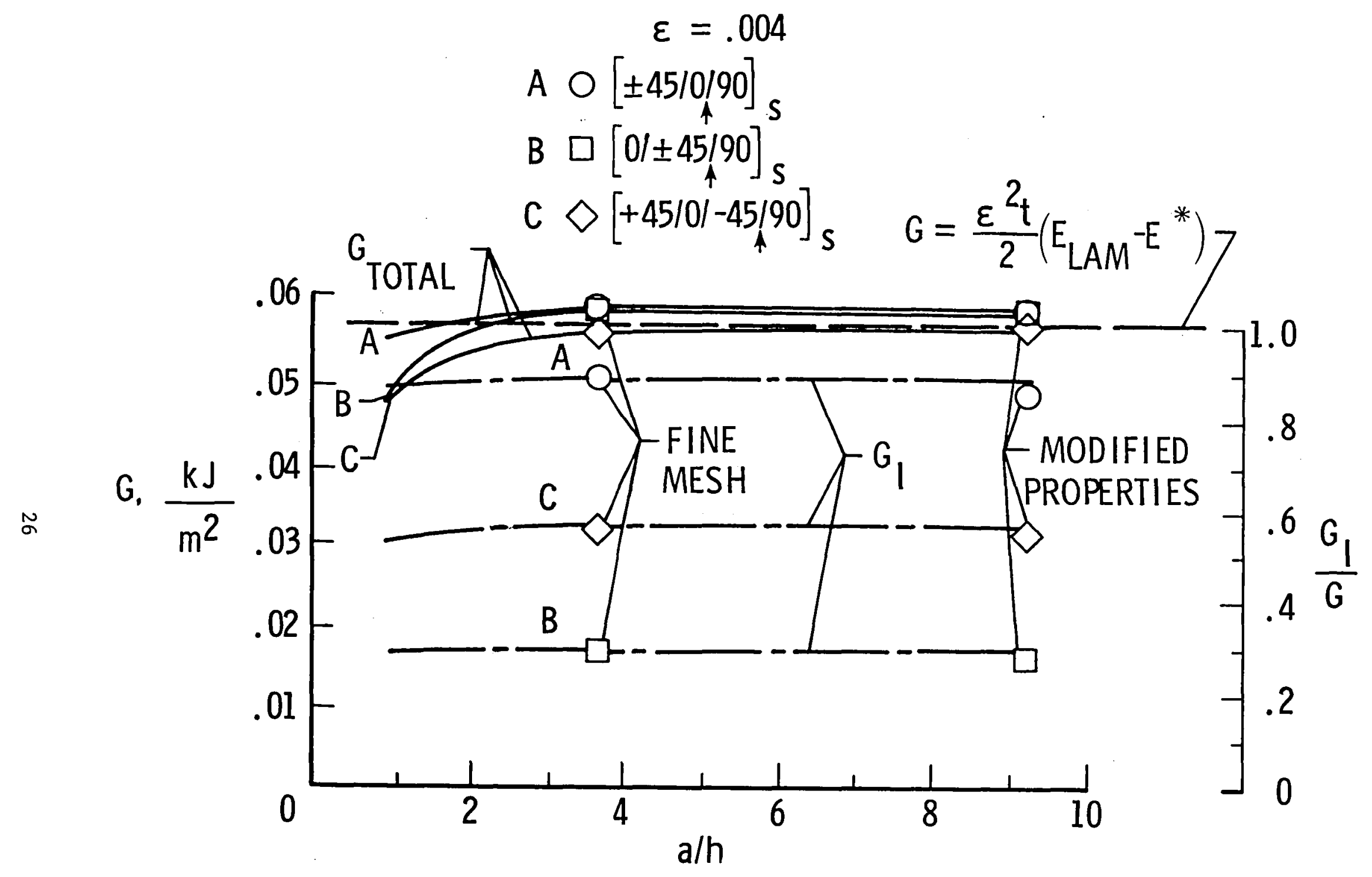

Fig. 4--Strain-energy-release rates from finite-element analysis. 


\section{T300/5208 GRAPHITE EPOXY}

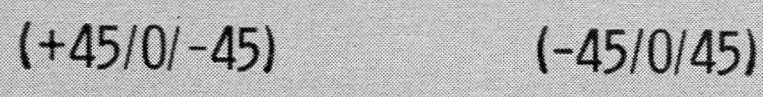

$(0 /+45)-45)$

$(-45 /+45 / 0)$

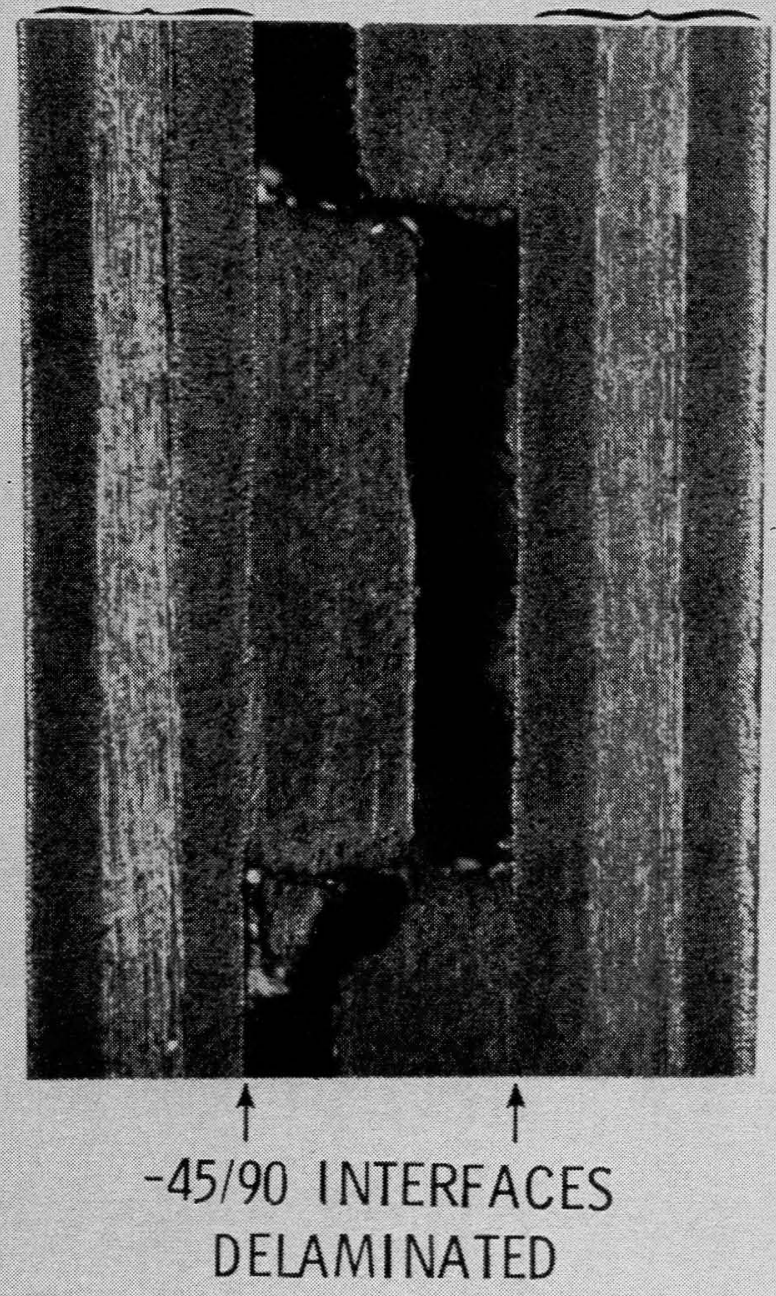

$[+45 / 0 /-45 / 90]_{S}$

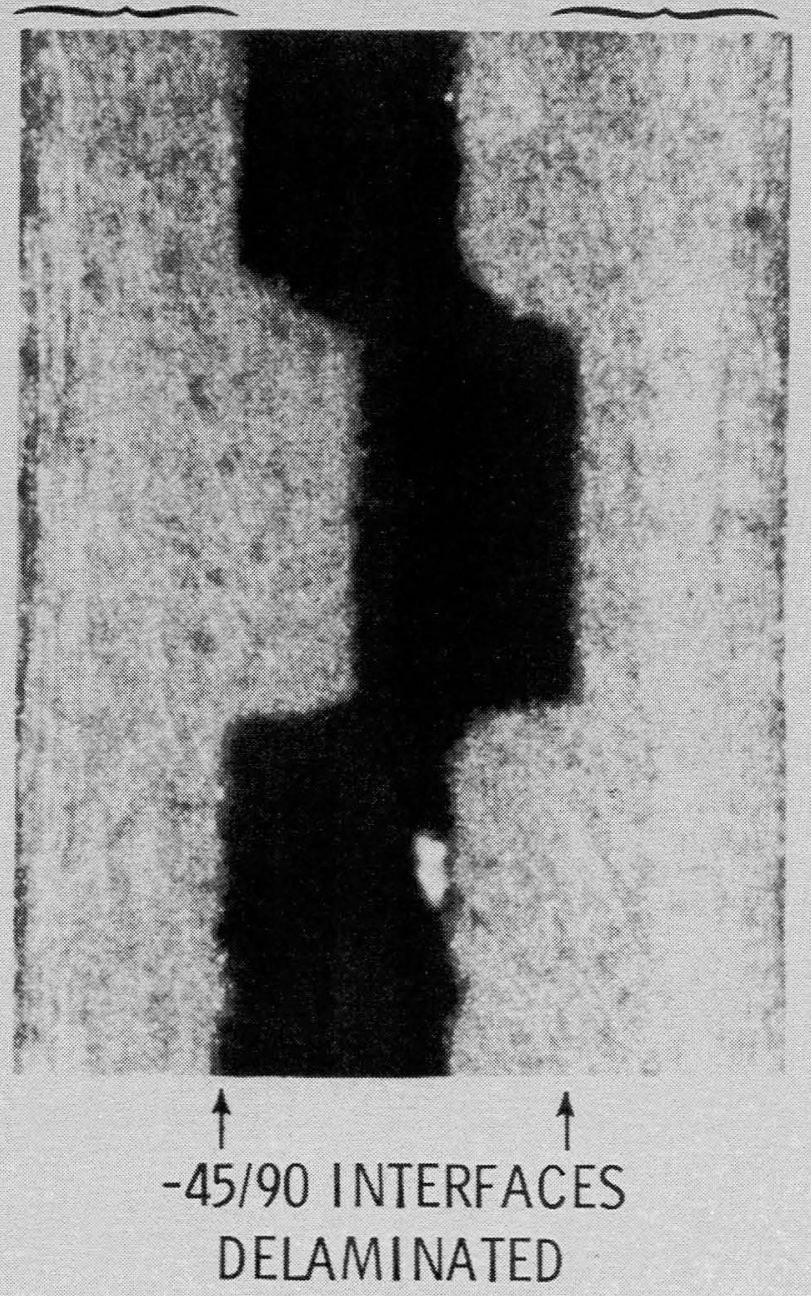

$$
[0 / \pm 45 / 90]_{s}
$$

Fig. 5--Delaminated straight edges, $[+45 / 0 /-45 / 90]_{S}$ and $[0 / \pm 45 / 90]_{S} \mathrm{~T} 300 / 5208$ laminates. 


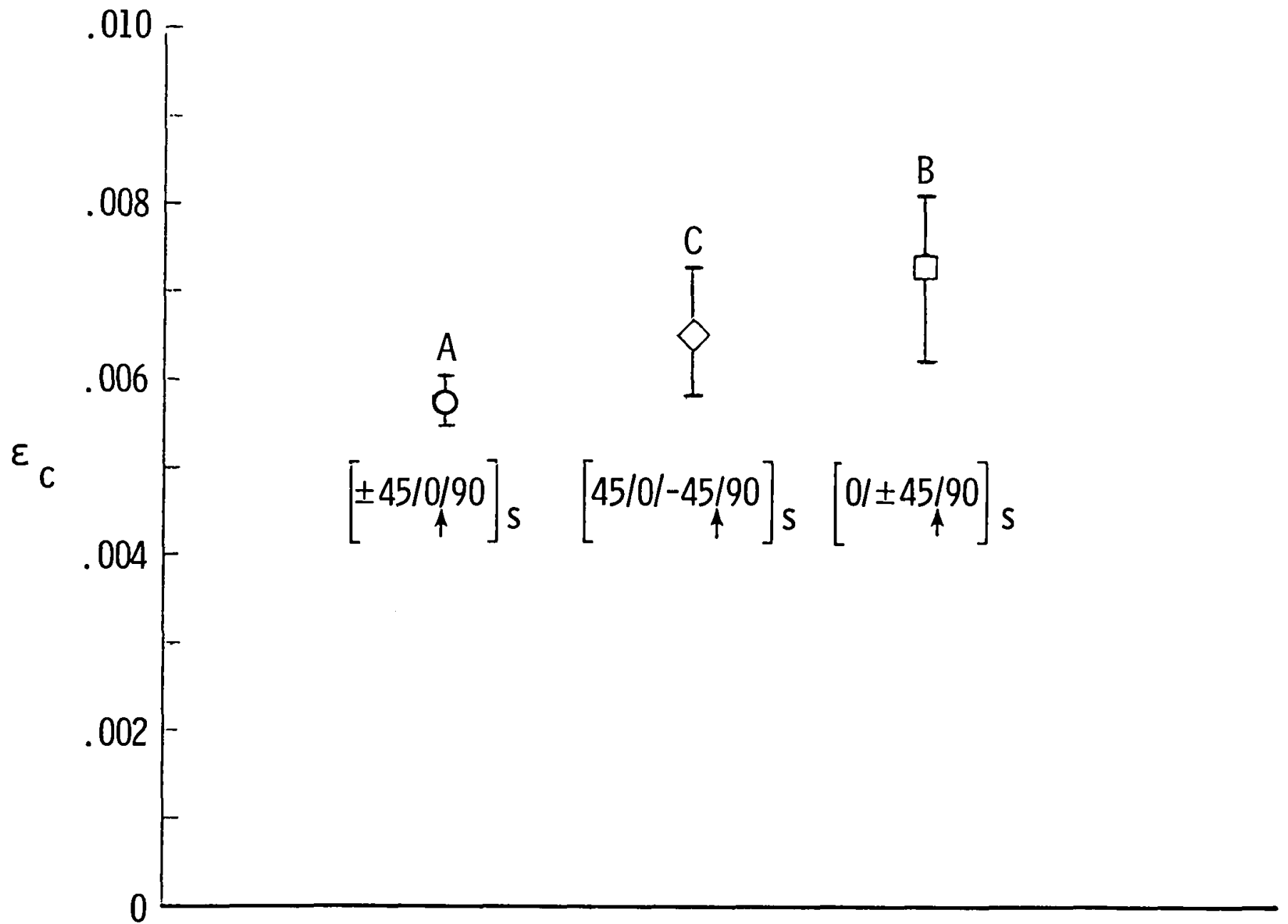

Fig. 6--Delamination onset strains for T300/5208 laminates. 


\section{T 300/5208 GRAPHITE EPOXY}

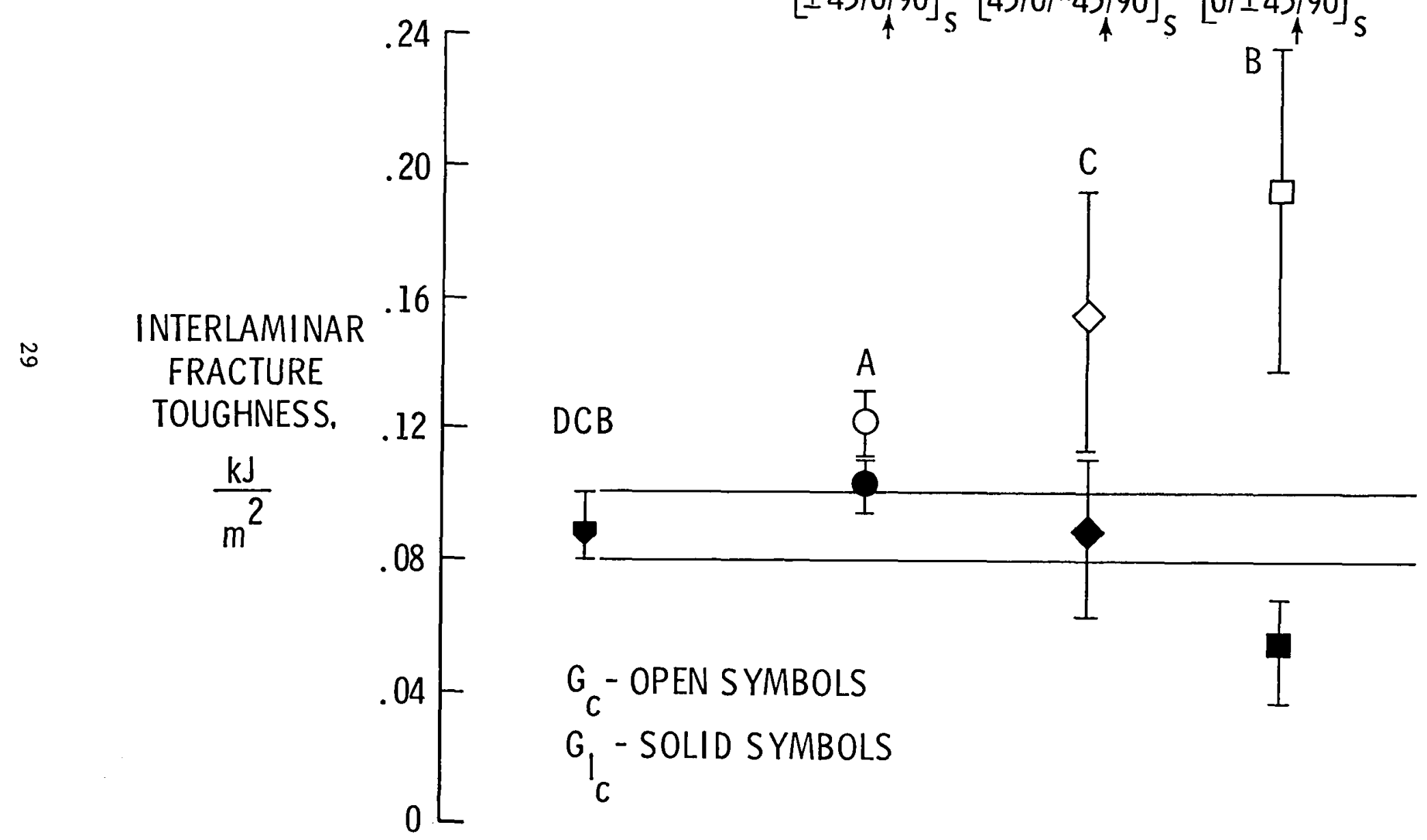

Fig. 7--Comparison of interlaminar fracture toughness measurements for T300/5208. 


\section{T300/5208 GRAPHITE EPOXY}

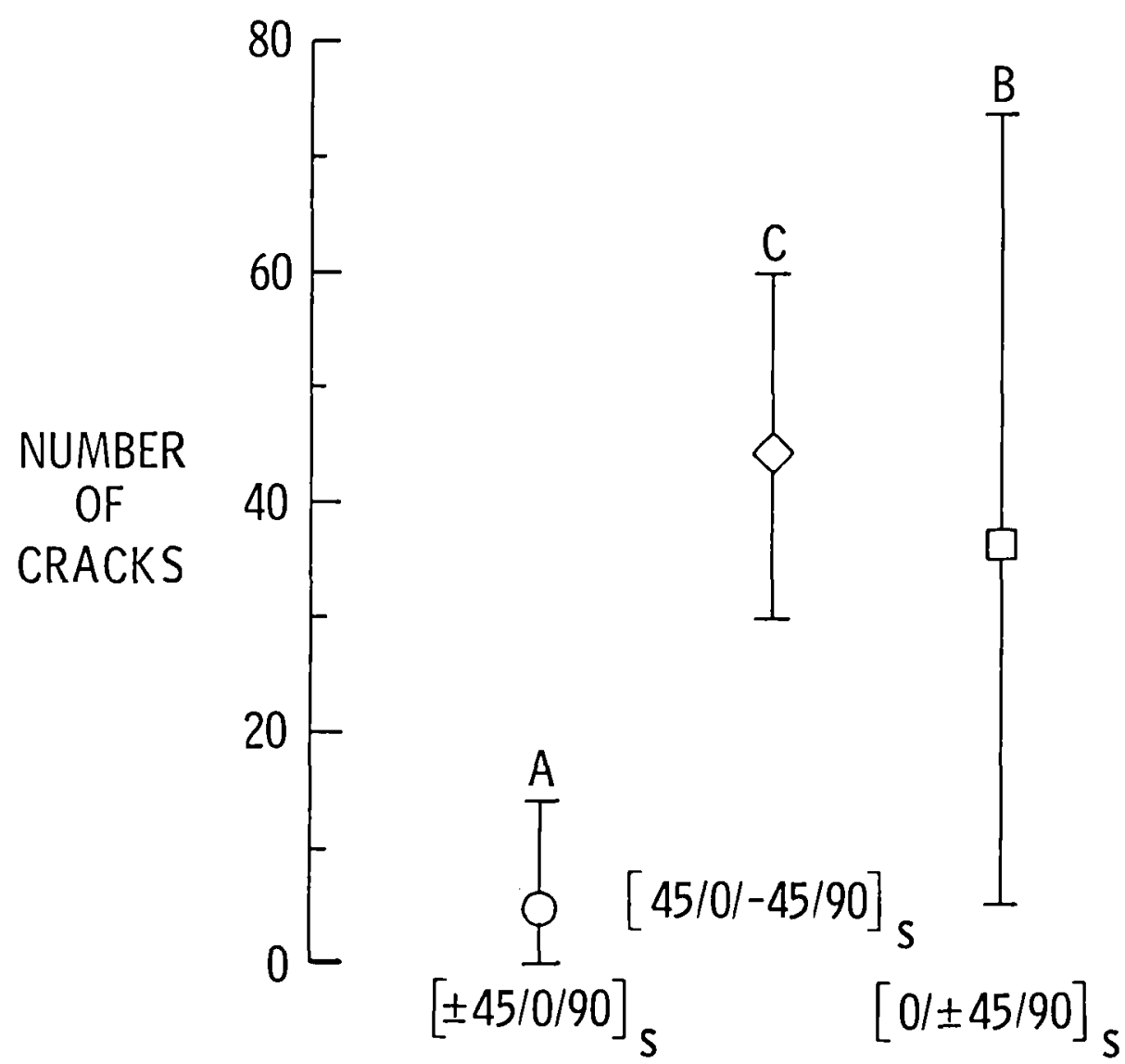

Fig. 8--Number of $90^{\circ}$ cracks before delamination, T300/5208. 
F.E.M.

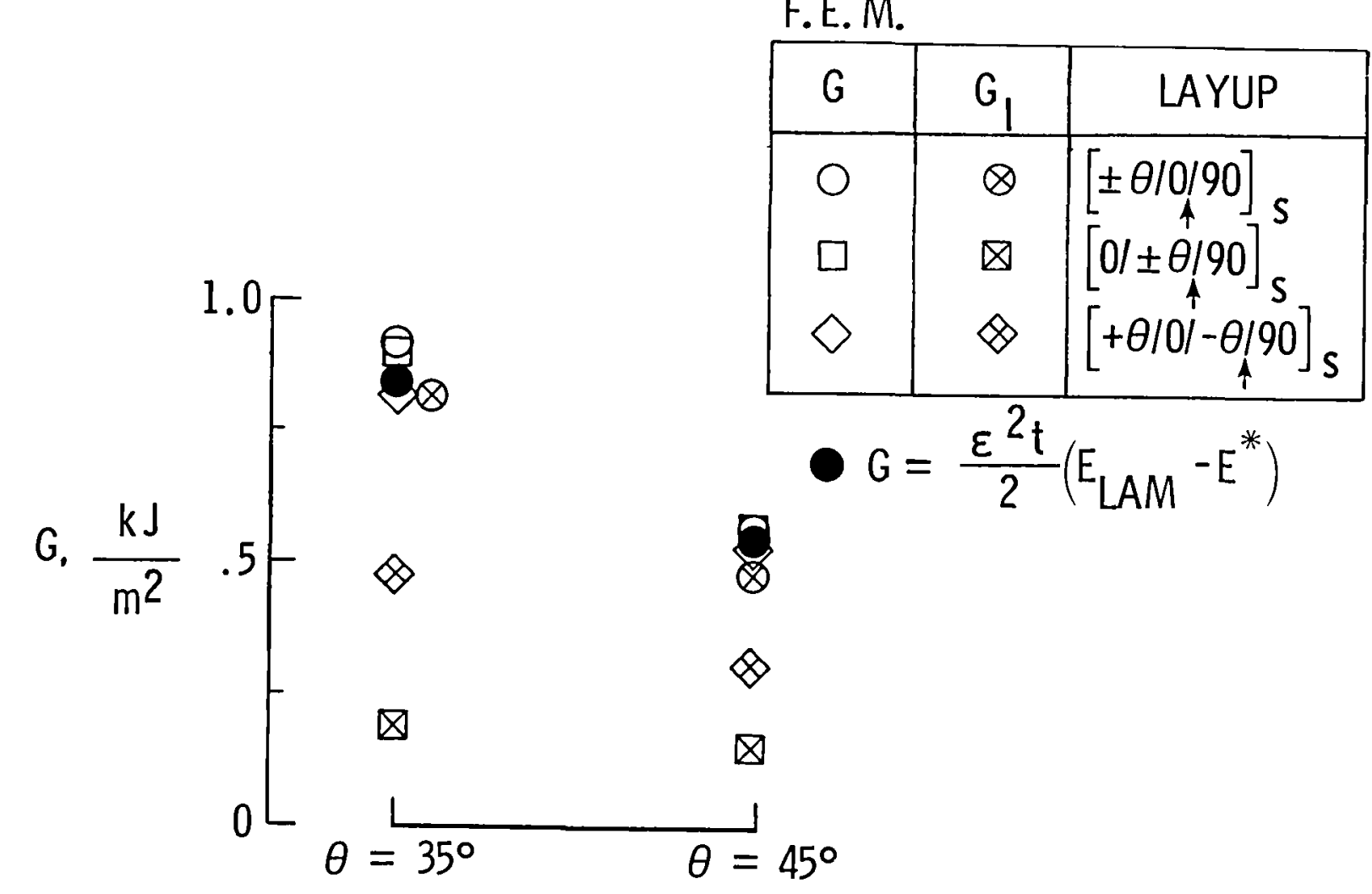

Fig. 9--Strain-energy-release rates for $[ \pm \theta / 0 / 90]_{\text {s }}$ laminate families. 


\section{C6000/H205 GRAPHITE EPOXY}

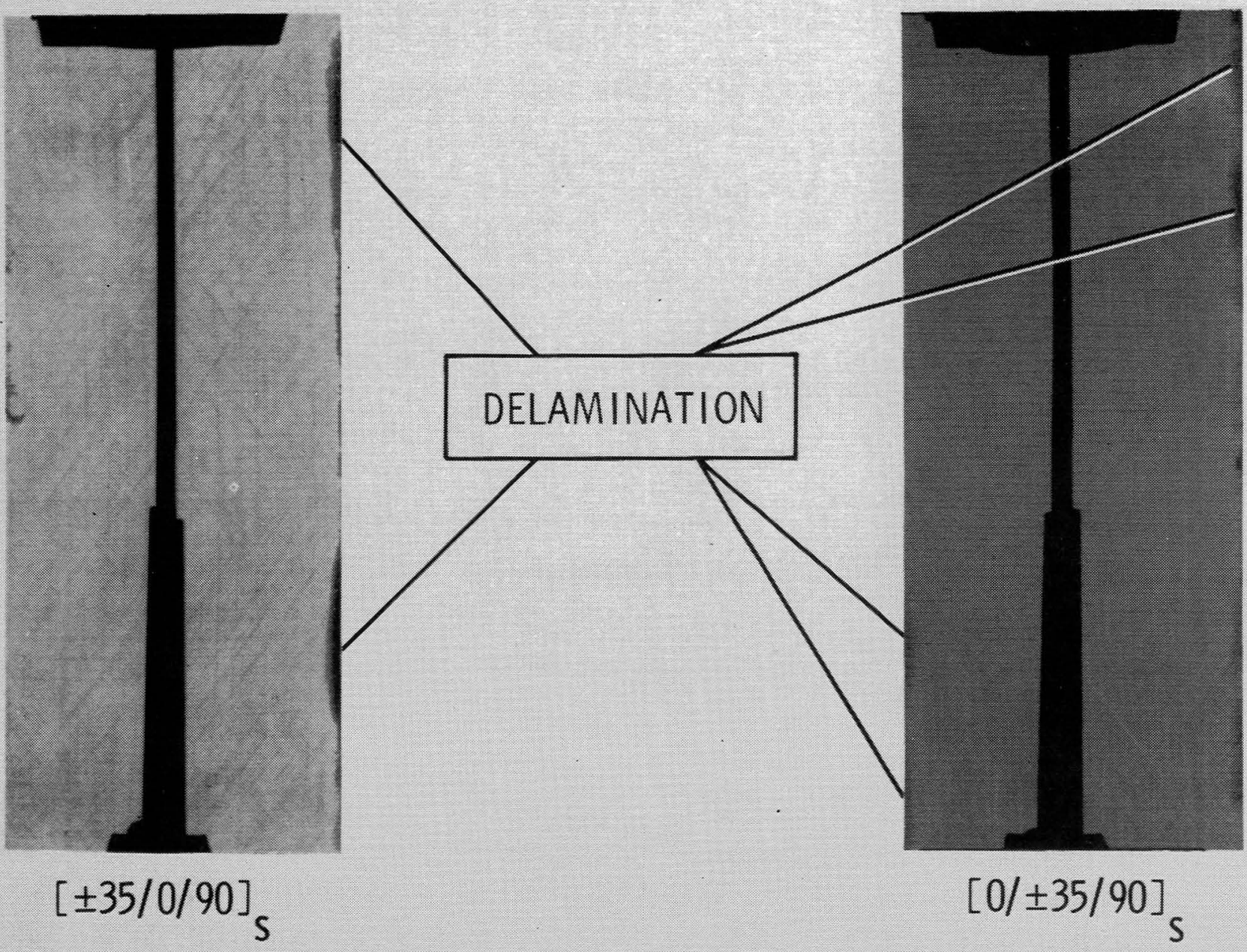

Fig. 10--Radiographs showing delamination onset in fatigue. 
C6000/H205 GRAPHITE EPOXY

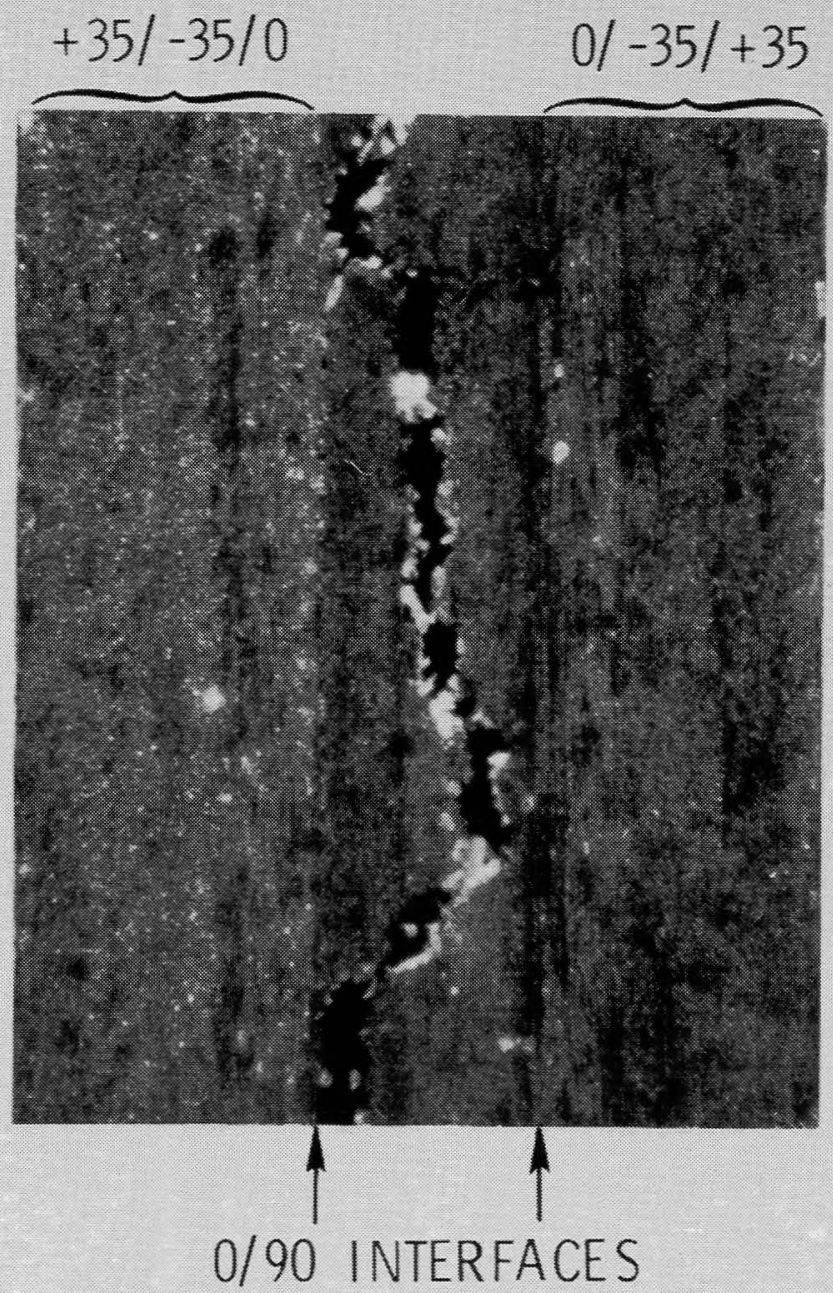

DELAMINATED

$[ \pm 35 / 0 / 90]_{S}$

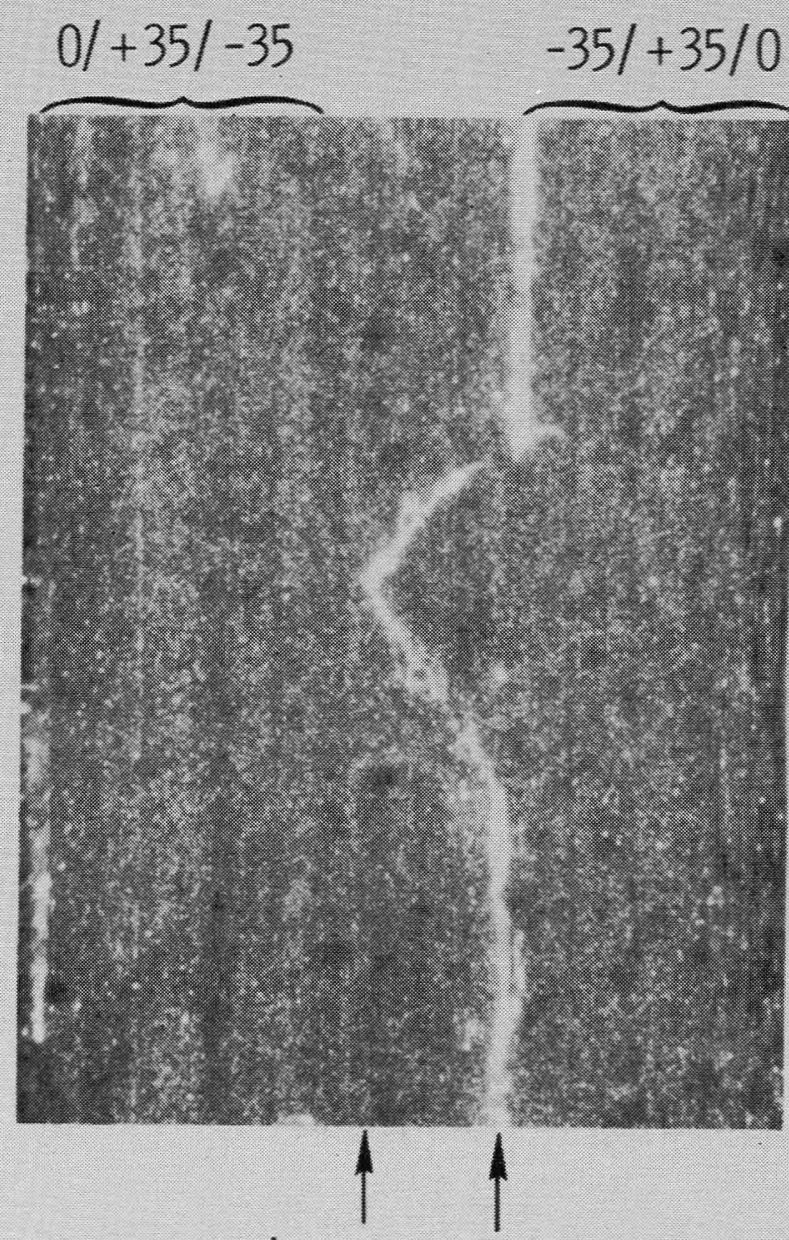

-35/90 INTERFACES

DELAMINATED

$[0 / \pm 35 / 90]_{S}$

Fig. 11--Delaminated straight edges after fatigue, C6000/H205. 


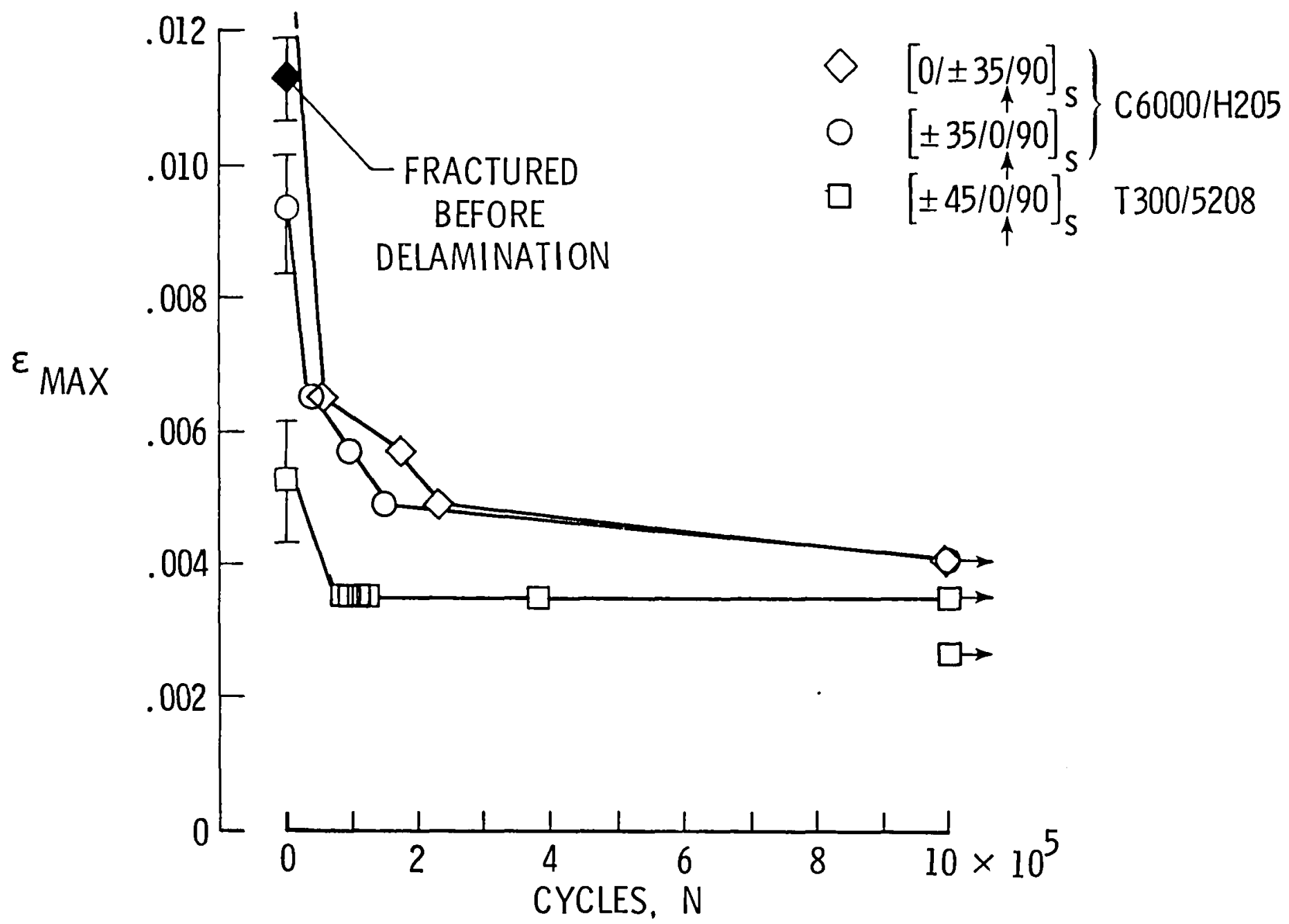

Fig. 12--Delamination onset as a function of strain and fatigue cycles. 


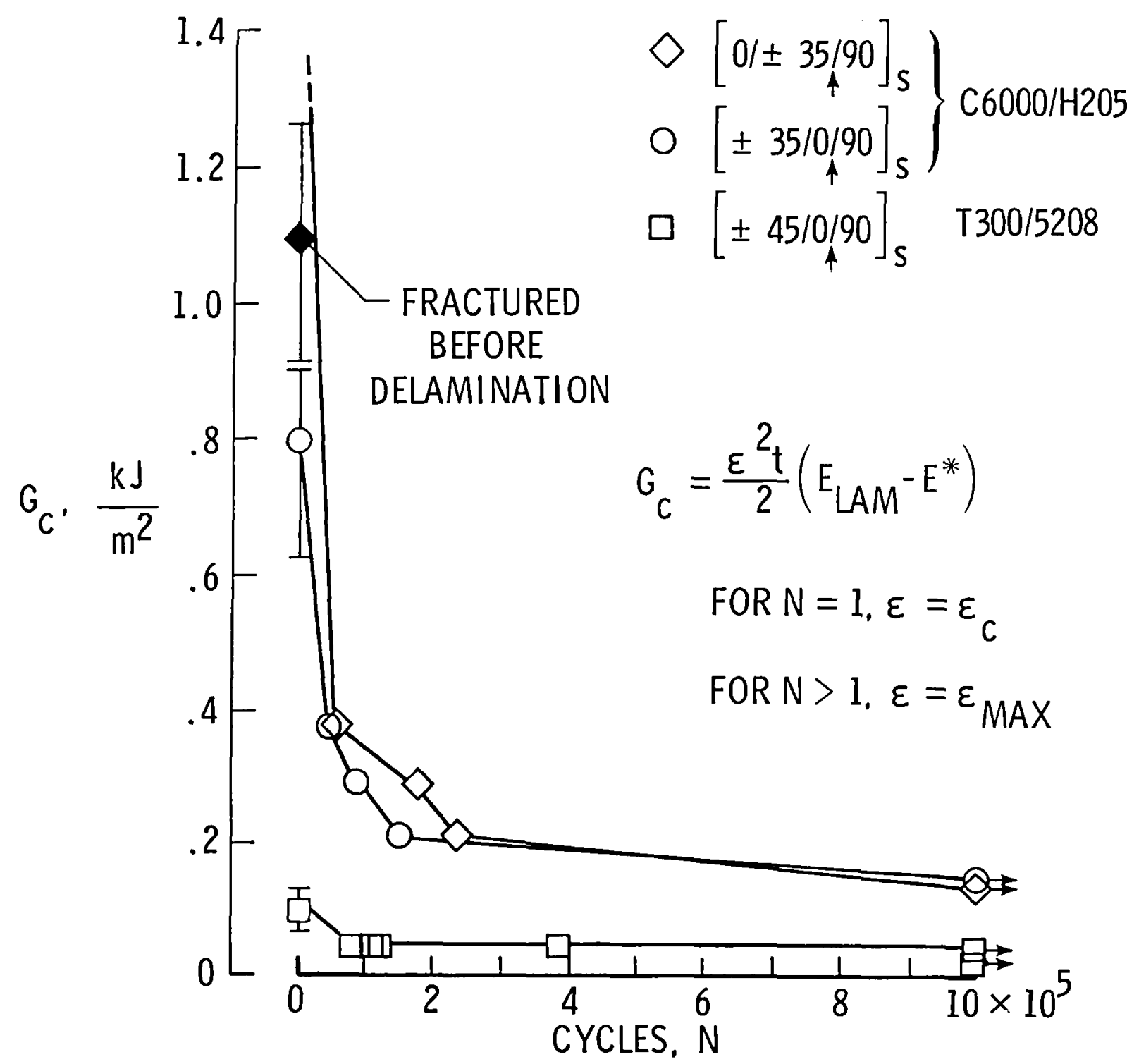

Fig. 13--Critical $G_{c}$ as a function of fatigue cycles. 


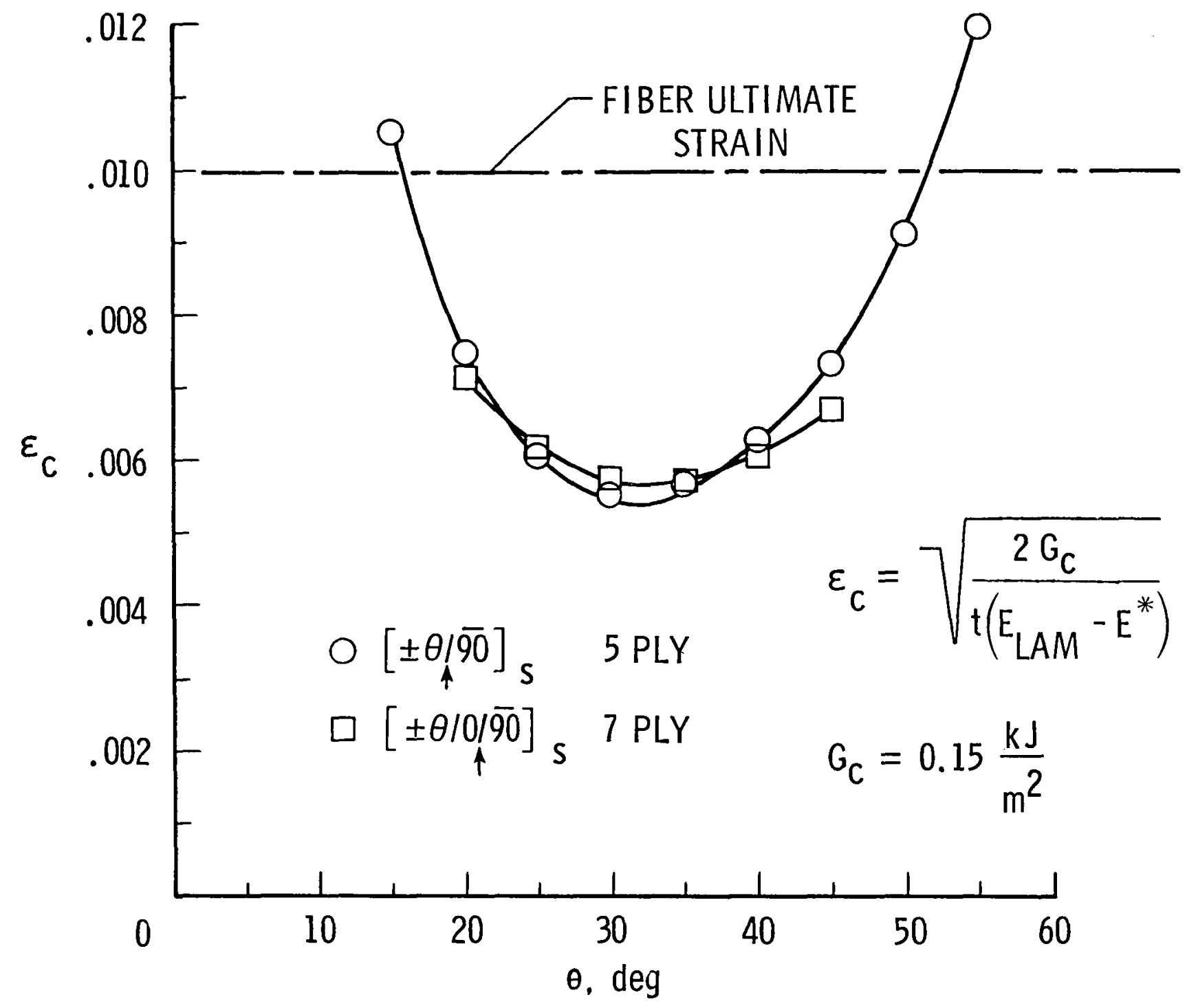

Fig. 14--Parametric study of variation in delamination onset strains with layup. 


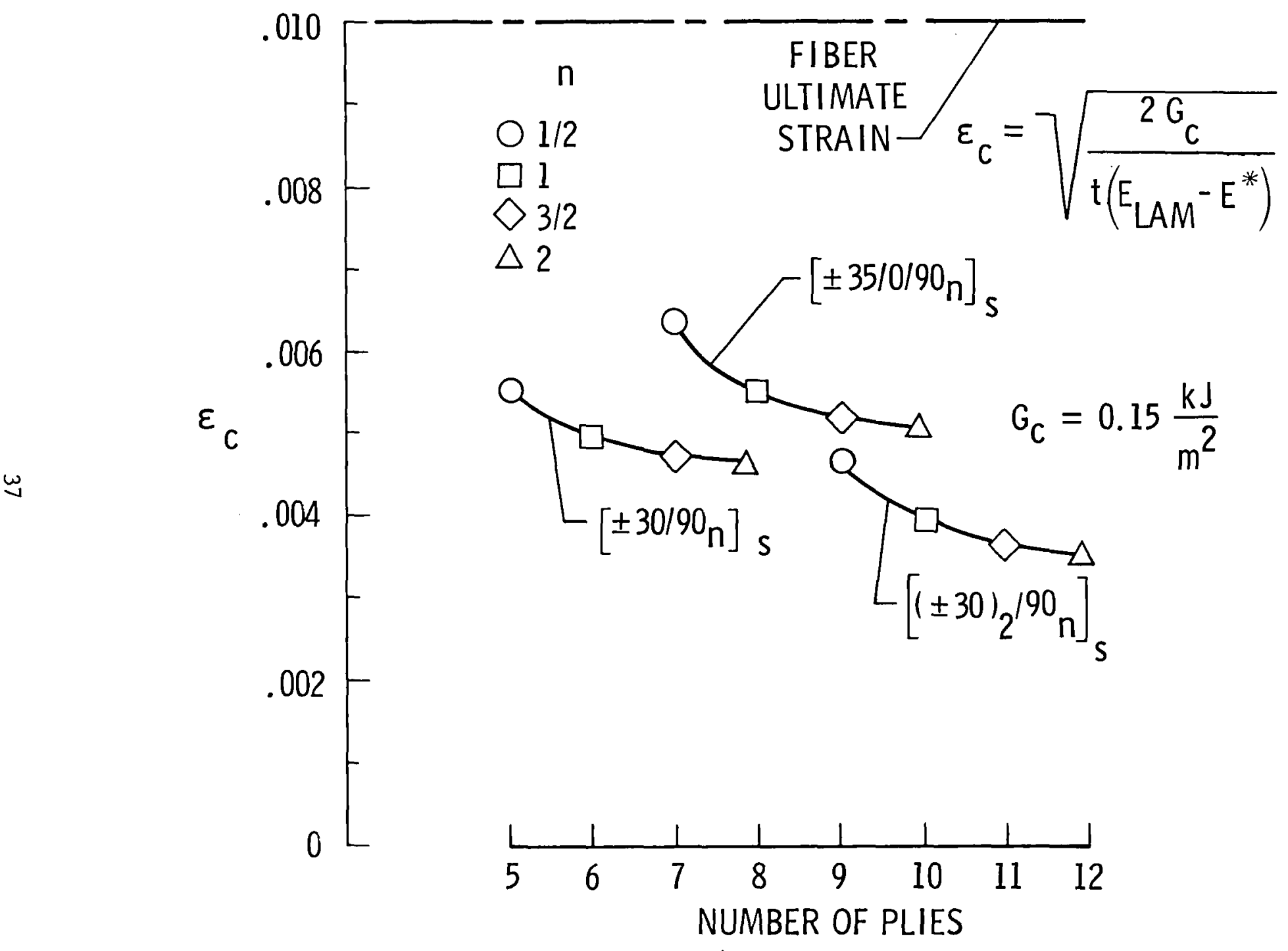

西

Fig. 15--Parametric study of variation in delamination onset strains with thickness. 




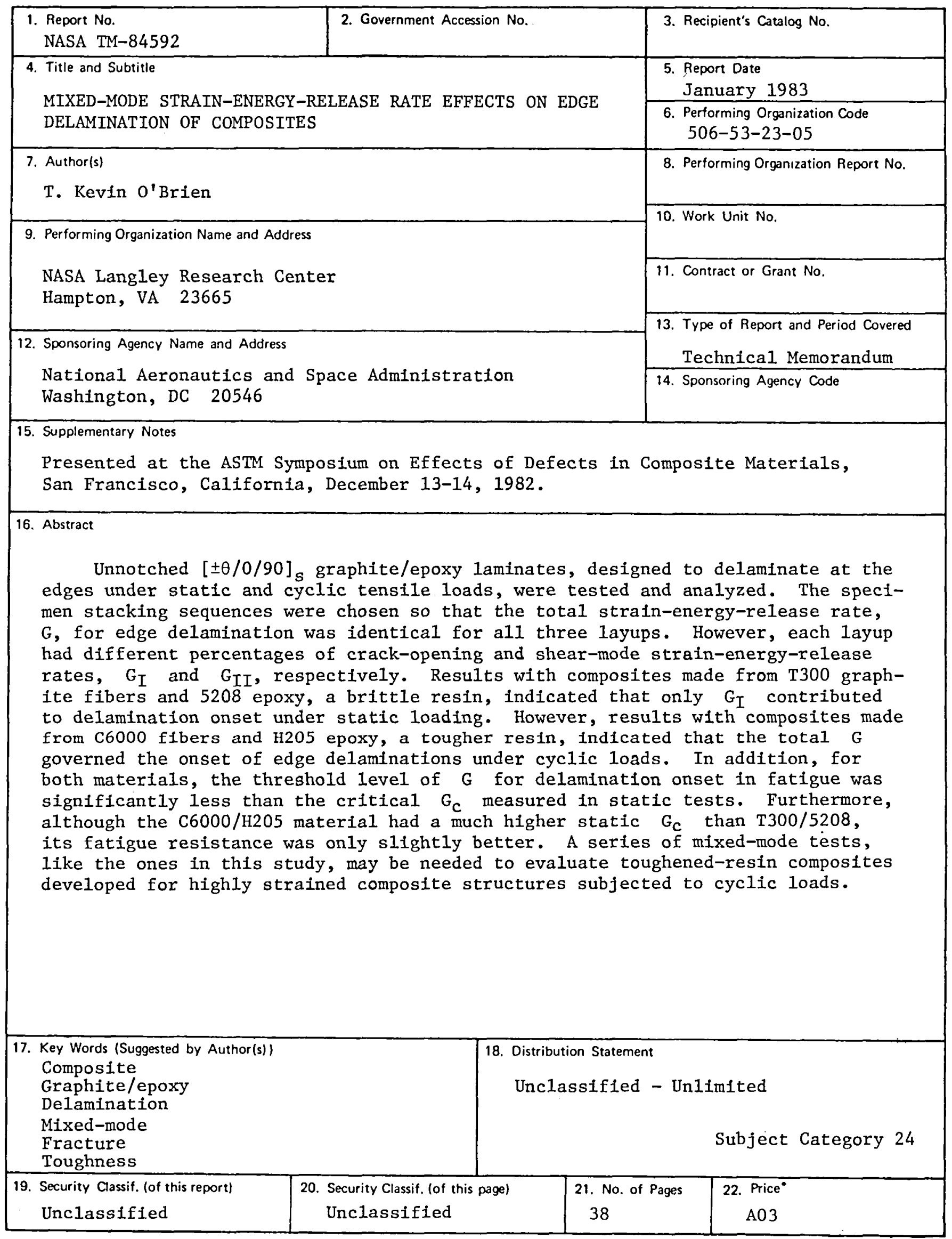

${ }^{*}$ For sale by the National Technical Information Service, Springfield, Virginia 22161 
